\title{
Complementary Configuration and Optimal Energy Flow of CCHP-ORC Systems Using a Matrix Modeling Approach
}

\author{
Wencong Huang, ${ }^{1,2}$ Yufang Chang $\mathbb{D}^{2},{ }^{2}$ and Youxin Yuan ${ }^{1}$ \\ ${ }^{1}$ School of Automation, Wuhan University of Technology, 122 Luoshi Road, Wuhan 430070, China \\ ${ }^{2}$ Hubei Key Laboratory for High-Efficiency Utilization of Solar Energy and Operation Control of Energy Storage System, \\ Hubei University of Technology, 28 Nanli Road, Wuhan, Hubei 430068, China
}

Correspondence should be addressed to Yufang Chang; changyf@hbut.edu.cn

Received 16 January 2019; Revised 13 March 2019; Accepted 28 March 2019; Published 18 April 2019

Guest Editor: Xiaoqing Bai

Copyright (c) 2019 Wencong Huang et al. This is an open access article distributed under the Creative Commons Attribution License, which permits unrestricted use, distribution, and reproduction in any medium, provided the original work is properly cited.

\begin{abstract}
A mass of thermal energy from the combined cooling, heating, and power (CCHP) system will be wasted by the buildings with low ratio of heat to power demand. To further improve the using efficiency of the excess thermal energy, an active method, which adds the organic Rankine cycle (ORC) equipment in the CCHP system, is configured. A complementary configuration of this $\mathrm{CCHP}-\mathrm{ORC}$ is also investigated. This paper presents a matrix modeling approach to establish a mathematical model of the CCHPORC system. The CCHP-ORC system can be viewed as a multiple input and multiple output (MIMO) model. Energy conversion of the system components is described as the efficiency matrices. Energy flow between the system components is described as dispatch matrices. Energy conversion and flow from the system input to output are modeled by a conversion matrix. The objective function and the constraints of the system are determined. The optimal operation strategies are obtained by solving the optimization problem of minimizing the evaluation criteria function. Comprehensive case studies are conducted based on a hypothetical CCHPORC system. The study results reveal that the effectiveness and economic efficiency of the proposed approaches outperform those obtained from conventional CCHP systems.
\end{abstract}

\section{Introduction}

According to the statistical data from the Energy Information Administration of the U.S. Department of Energy, in many countries, building energy consumption accounts for about $36 \%$ of the total energy consumption, and nearly $30 \%$ of greenhouse gas (GHG) emissions [1]. Particularly in China, the building energy consumption has an annual growth rate over $10 \%$ with the rapid development of economy [2,3]. The increasing building energy consumption has led to serious building-related problems such as restricting economic development, exacerbating energy crisis, and environmental issues such as greenhouse effect and air pollution. To deal with these problems, combined cooling, heating and power (CCHP) systems which can improve energy utilization efficiency and reduce GHG emissions are developed.

A CCHP system is an integrated energy supply system, which can also be referred to as the trigeneration system [4]. It provides building users electricity, cooling energy, and heating energy by installing the power generation unit (PGU) $[5,6]$. The CCHP system makes use of the rejected heat from the PGU to generate thermal energy for cooling and heating demands $[7,8]$. As a result, the overall fuel energy utilization efficiency of CCHP systems can reach 70\%$90 \%$, which is significantly higher than that of separation production (SP) systems $[9,10]$. As shown in the literature, CCHP systems have been broadly applied in office buildings, hotels, hospitals, commercial malls, and other building types.

Performance of the CCHP system depends on the system structure and the operation strategy. In [11], the authors propose a new CCHP system structure with both absorption and electric chillers to provide more flexibility in supplying energy. Four typical CCHP systems with existing technologies for various size ranges are illustrated in [12]. With the development of the renewable energy, solar-integrated CCHP systems [13-17], SOFC-trigeneration systems [18, 19], and biomass-trigeneration system [20] are studied. 
Once the system structure is determined and implemented, the operation strategy is the crucial factor for the CCHP system design. There are two popular operation strategies [21-24]: following the electric load (FEL) and following the thermal load (FTL). However, as illustrated in the literature [11] both of the FEL and FTL strategies inherently waste a certain amount of energy. Therefore, designing an optimal operation strategy to improve the energy utilization efficiency by reducing the energy waste is urged.

Operation strategy design relies on the selection of evaluation criteria, which should be aligned with the stakeholders' objectives. Energy savings and environmental impacts are two popular aspects when constructing evaluation criteria. Fumo et al. proposed the evaluation criteria considering the primary energy consumption saving (PECS) and carbon dioxide emission reduction (CDER) [25, 26]. Li et al. established a mix-integer nonlinear programming (MINLP) model to evaluate economic efficiency and sensitivity of CCHP systems [27]. Wang et al. studied the energetic and environmental benefits of the CCHP system in comparison to SP systems based on a particle swarm optimization algorithm [28]. Jing et al. estimated the PEC and pollution emissions of the BCHP system in FEL and FTL operation strategies based on life cycle assessment (LCA) $[29,30]$.

For an existing CCHP system, when the electricity to thermal energy requirement ratio of building users is exactly equal to the output ratio of the PGU, the maximum efficiency of the CCHP system is achieved [31]. However, this ideal situation rarely happens due to the random variation of energy requirements. When the supply is insufficient, adding extra energy (fuel or electricity) is a direct treatment. However, when the supply exceeds the demand, the situation becomes complicated. In the case surplus electricity is generated, it can be sold back to power grid or converted to thermal energy. Similarly, the excess thermal energy can be stored in thermal storage units or converted to electricity by some special equipment, such as organic ranking cycle (ORC). In this paper, an active excess thermal energy treatment method which uses an ORC to convert the excess thermal to electricity is investigated.

In recent years, more attention has been put on the ORC system. A complementary structure of CCHP-ORC system is configured in [31,32]. A biomass fuelled trigeneration system integrated with ORC is studied in [33]. Three trigeneration systems, combined SOFC with ORC, combined biomass combustor with ORC, and combined solar collectors with ORC, are analyzed in [34]. Liu et al. researched five kinds of building in Shanghai and evaluated the CCHP-ORC system [35]. The aforementioned literature shows that the ORC technology has advantages in using the thermal energy and its combination with trigeneration system has good application prospects. So we are going to adopt the CCHPORC structure which uses the gas turbine as PGU, an ORC as waste heat recycle equipment, and electric and absorption chillers as hybrid chillers. The advantages of our CCHP-ORC system are reflected by the higher energy utilization, and the adjustability of the electricity to thermal energy output ratio.

When the structure of the CCHP-ORC system is configured, the operation strategy should be designed. Firstly, the mathematical model of the CCHP-ORC system should be established. From the perspective of control theory, the CCHP-ORC system can be treated as the connection between the energy input and the building users' demand. We consider using transfer function in control theory to describe this input-output relation. Because the energy input includes fuel and electricity from the power grid, and the building users' demand includes cooling, heating, and power, the CCHPORC system is a multiple input and multiple output (MIMO) system. In [36], the concepts of dispatch factors and coupling matrix are used to describe the system, and the power flow and operation strategy are optimized using Karush-KuhnTucker (KKT) conditions. In [37], the authors model the system by introducing the concepts of bifurcations, junctions, and the backtracking. However these modeling methods are too complicated.

The main contribution of this paper is that a more intuitive and comprehensive approach, a matrix transfer function modeling approach (referred to as matrix modeling approach), is proposed to model the CCHP-ORC system. Based on the matrix modeled system, sequential quadratic programming (SPQ) algorithm is adopted to optimize the linear objective function, which is subjected to the nonlinear equalities and inequalities. The result of the optimization problem is the optimal flow and operation strategy for the CCHP-ORC.

This paper is organized as follows. The configuration and matrix modeling of the CCHP-ORC system are described in Section 2. In Section 3, the performance criteria for the CCHP-ORC system are presented and the optimization problem is established. Finally, the effectiveness of the system configuration and operation strategy are verified through a case study of a hypothetical office building in Section 4 . Section 5 concludes this paper.

\section{System Configuration and Matrix Modeling}

In this section, an optimal CCHP-ORC structure and an intuitive matrix modeling of the CCHP-ORC system will be introduced. In order to make full use of energy and improve the flexibility of energy supply, the configuration of the CCHP-ORC system is presented in Figure 1.

In addition to traditional equipment, a complementary ORC and an electric chiller are added as important components which can not only utilize the excess thermal energy but also dynamically adjust the electricity to thermal energy output ratio of the entire system. In Figure 1 , when $Q_{r}+Q_{b}>$ $Q_{h r c}+Q_{h r h}$, the excess thermal energy exists. The ORC is used to convert the excess thermal to electricity. The cooling load is provided by absorption and electric chillers. The electric chiller has a high coefficient of performance (COP) which leads to a high cooling efficiency. The output of the ORC and the electric chiller can be adjusted dynamically to keep the CCHP-ORC system running at the matched status according to the users' energy requirements.

2.1. Efficiency Matrices of System Components. The energy conversion of the components in the CCHP-ORC system 


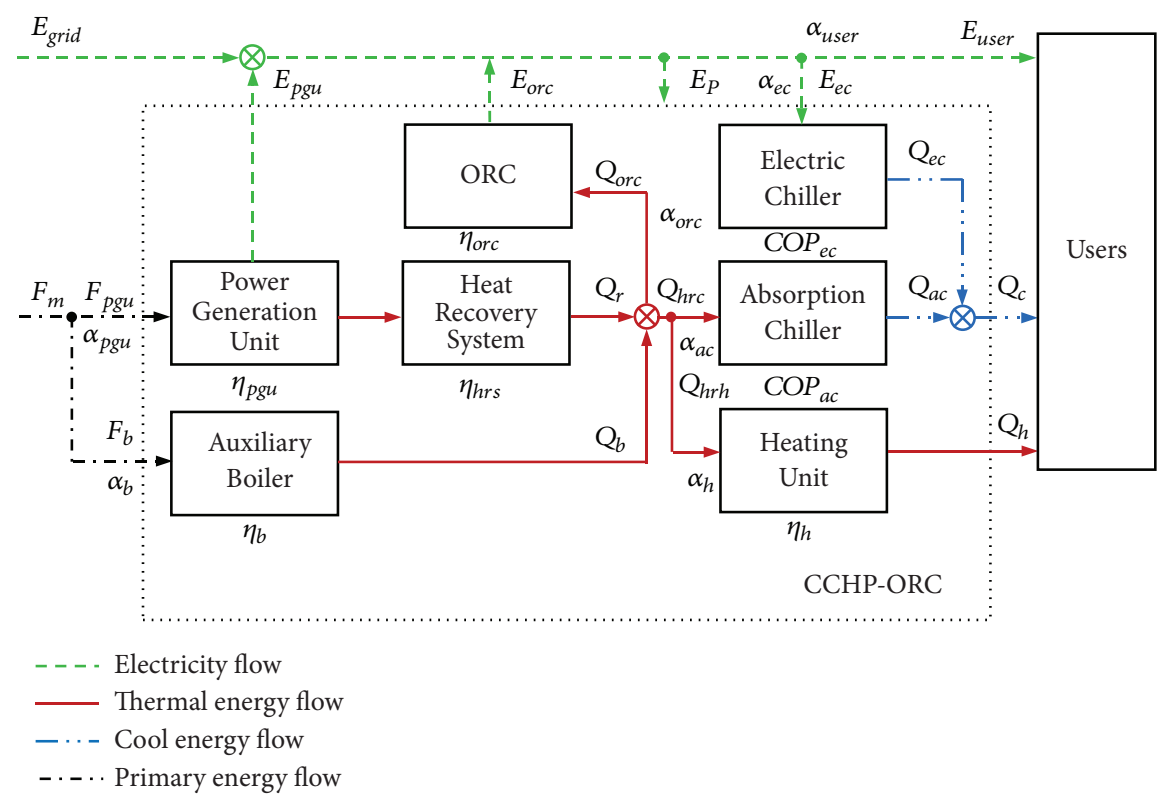

FIGURE 1: Structure diagram of a CCHP-ORC system.

can be described using efficiency matrices, namely, coupling matrices. In this paper, $u$ is an equipment set and equipment $m \in u, F, E, Q_{c}$, and $Q_{h}$ denote the fuel, electricity, cooling energy, and heating energy, respectively. The input and the output of the component $m$ are defined as $V_{i}^{m}=$ $\left[F_{i}^{m} E_{i}^{m} Q_{c i}^{m} Q_{h i}^{m}\right]^{\top}$ and $V_{o}^{m}=\left[F_{o}^{m} E_{o}^{m} Q_{c o}^{m} Q_{h o}^{m}\right]^{\top}$, respectively. So the input-output relation of the component $m$ can be described as

$$
V_{o}^{m}=H^{m} V_{i}^{m},
$$

where $H^{m}$ is the efficiency matrix of the component $m$.

Consequently, the input-output relation of the ORC can be represented in the following matrix form:

$$
\left[\begin{array}{c}
0 \\
E_{o}^{\text {orc }} \\
0 \\
0
\end{array}\right]=\left[\begin{array}{cccc}
0 & 0 & 0 & 0 \\
0 & 0 & 0 & C O P_{\text {orc }} \\
0 & 0 & 0 & 0 \\
0 & 0 & 0 & 0
\end{array}\right]\left[\begin{array}{c}
0 \\
0 \\
0 \\
Q_{h i}^{\text {orc }}
\end{array}\right]=H^{\text {orc }} V_{i}^{\text {orc }} .
$$

Following the same procedure, efficiency matrices for the PGU, auxiliary boiler, heat recovery system, heating unit, electric chiller, and absorption chiller can be obtained as

$$
\begin{aligned}
H^{p g u} & =\left[\begin{array}{cccc}
0 & 0 & 0 & 0 \\
\eta_{p g u} & 0 & 0 & 0 \\
0 & 0 & 0 & 0 \\
1-\eta_{p g u} & 0 & 0 & 0
\end{array}\right], \\
H^{b} & =\left[\begin{array}{llll}
0 & 0 & 0 & 0 \\
0 & 0 & 0 & 0 \\
0 & 0 & 0 & 0 \\
\eta_{b} & 0 & 0 & 0
\end{array}\right],
\end{aligned}
$$

$$
\begin{aligned}
H^{h r s} & =\left[\begin{array}{llll}
0 & 0 & 0 & 0 \\
0 & 0 & 0 & 0 \\
0 & 0 & 0 & 0 \\
0 & 0 & 0 & \eta_{h r s}
\end{array}\right], \\
H^{h} & =\left[\begin{array}{llll}
0 & 0 & 0 & 0 \\
0 & 0 & 0 & 0 \\
0 & 0 & 0 & 0 \\
0 & 0 & 0 & \eta_{h}
\end{array}\right], \\
H^{e c} & =\left[\begin{array}{lllll}
0 & 0 & 0 & 0 \\
0 & 0 & 0 & 0 \\
0 & C O P_{e c} & 0 & 0 \\
0 & 0 & 0 & 0
\end{array}\right], \\
H^{a c} & =\left[\begin{array}{lllll}
0 & 0 & 0 & 0 \\
0 & 0 & 0 & 0 \\
0 & 0 & 0 & C O P_{a c} \\
0 & 0 & 0 & 0
\end{array}\right] .
\end{aligned}
$$

Each efficiency matrix represents the performance of the energy conversion of each component in the CCHP-ORC system.

2.2. Dispatch Matrices of System. The dispatch matrices indicate the energy flow between the components in the system. Usually, the dispatch factors exist at the bifurcations of the system. For example in Figure 1, the thermal energy produced by the heat recovery system and the auxiliary boiler will be 
separated into three parts: one for the absorption chiller, one for the heating unit, and the last one for the ORC. Let $\alpha_{a c}, \alpha_{h}$, and $\alpha_{\text {orc }}$ denote the dispatch factors for the absorption chiller, the heating unit, and the ORC, respectively. Then we have

$$
\begin{aligned}
& Q_{h r c}=\alpha_{a c}\left(Q_{r}+Q_{b}\right), \\
& Q_{h r h}=\alpha_{h}\left(Q_{r}+Q_{b}\right), \\
& Q_{o r c}=\alpha_{o r c}\left(Q_{r}+Q_{b}\right),
\end{aligned}
$$

subject to

$$
\begin{aligned}
& 0 \leq \alpha_{a c}+\alpha_{h}+\alpha_{o r c} \leq 1, \\
& 0 \leq \alpha_{a c} \leq 1, \\
& 0 \leq \alpha_{h} \leq 1, \\
& 0 \leq \alpha_{o r c} \leq 1 .
\end{aligned}
$$

At the ORC side, we have

$$
Q_{o r c}=\left[\alpha_{p g u}\left(1-\eta_{p g u}\right) \eta_{h r s}+\alpha_{b} \eta_{b}\right] \alpha_{o r c} F_{m}
$$

where $\alpha_{p g u}$ and $\alpha_{b}$ denote the dispatch factors for the PGU and the auxiliary boiler. To facilitate the later optimizationbased operation strategy design, (8) can be rewritten in a matrix form as

$$
\begin{aligned}
& V_{i}^{\text {orc }} \\
& =\left[\begin{array}{cccc}
0 & 0 & 0 & 0 \\
0 & 0 & 0 & 0 \\
0 & 0 & 0 & 0 \\
\alpha_{\text {orc }}\left[\alpha_{p g u}\left(1-\eta_{p g u}\right) \eta_{h r s}+\alpha_{b} \eta_{b}\right] & 0 & 0 & 0
\end{array}\right]\left[\begin{array}{c}
F_{m} \\
E_{\text {grid }} \\
0 \\
0
\end{array}\right] \\
& =T_{\text {orc }} V_{i}
\end{aligned}
$$

where $T_{\text {orc }}$ is the dispatch matrix for the ORC and $V_{i}$ is the system input.

By following the similar procedure, the dispatch matrices for the PGU, the auxiliary boiler, electric chiller, heat recovery system, heating unit, and absorption chiller can be defined as

$$
\begin{aligned}
T_{p g u} & =\left[\begin{array}{cccc}
\alpha_{p g u} & 0 & 0 & 0 \\
0 & 0 & 0 & 0 \\
0 & 0 & 0 & 0 \\
0 & 0 & 0 & 0
\end{array}\right], \\
T_{b} & =\left[\begin{array}{llll}
\alpha_{b} & 0 & 0 & 0 \\
0 & 0 & 0 & 0 \\
0 & 0 & 0 & 0 \\
0 & 0 & 0 & 0
\end{array}\right],
\end{aligned}
$$

$$
\begin{aligned}
T_{e c} & =\left[\begin{array}{cccc}
0 & 0 & 0 & 0 \\
0 & \alpha_{e c} & 0 & 0 \\
0 & 0 & 0 & 0 \\
0 & 0 & 0 & 0
\end{array}\right], \\
T_{h r s} & =\left[\begin{array}{ccccc}
0 & 0 & 0 & 0 \\
0 & 0 & 0 & 0 \\
0 & 0 & 0 & 0 \\
\alpha_{p g u}\left(1-\eta_{p g u}\right) & 0 & 0 & 0
\end{array}\right],
\end{aligned}
$$

$$
\begin{aligned}
& T_{h}=\left[\begin{array}{cccc}
0 & 0 & 0 & 0 \\
0 & 0 & 0 & 0 \\
0 & 0 & 0 & 0 \\
\alpha_{h}\left[\alpha_{p g u}\left(1-\eta_{p g u}\right) \eta_{h r s}+\alpha_{b} \eta_{b}\right] & 0 & 0 & 0
\end{array}\right] \text {, } \\
& T_{a c}=\left[\begin{array}{cccc}
0 & 0 & 0 & 0 \\
0 & 0 & 0 & 0 \\
0 & 0 & 0 & 0 \\
\alpha_{a c}\left[\alpha_{p g u}\left(1-\eta_{p g u}\right) \eta_{h r s}+\alpha_{b} \eta_{b}\right] & 0 & 0 & 0
\end{array}\right] \text {. }
\end{aligned}
$$

Similarly, in addition to (7a), (7b), (7c), and (7d), we have

$$
\begin{aligned}
& \alpha_{p g u}+\alpha_{b}=1, \\
& \alpha_{u s e r}+\alpha_{e c}=1, \\
& \alpha_{a c}+\alpha_{h}+\alpha_{o r c}=1, \\
& 0 \leq \alpha_{p g u}, \alpha_{b}, \alpha_{u s e r}, \alpha_{e c}, \alpha_{a c}, \alpha_{h}, \alpha_{o r c} \leq 1 .
\end{aligned}
$$

2.3. Conversion Matrix of the CCHP-ORC System. The CCHP-ORC system modeled in a matrix form can be viewed as an input-out model. The conversion matrix of the CCHPORC system describes the relationship between the input and the output and represents the energy flow procedure of the system. From Figure 1, the system input and output are defined as

$$
\begin{aligned}
V_{i} & =\left[\begin{array}{llll}
F_{m} & E_{\text {grid }} & Q_{c i} & Q_{h i}
\end{array}\right]^{\top}=\left[\begin{array}{llll}
F_{m} & E_{\text {grid }} & 0 & 0
\end{array}\right]^{\top}, \\
V_{o} & =\left[\begin{array}{llll}
F_{o} & E_{\text {user }} & Q_{c} & Q_{h}
\end{array}\right]^{\top}=\left[\begin{array}{llll}
0 & E_{\text {user }} & Q_{c} & Q_{h}
\end{array}\right]^{\top},
\end{aligned}
$$

respectively.

Then the conversion matrix of the CCHP-ORC system, $G$, can be defined as

$$
V_{o}=G V_{i}
$$

In order to obtain the conversion matrix $G$, the expression of the output elements, $E_{u s e r}, Q_{c}$, and $Q_{h}$, should be written as functions of the system input. Without the loss of generality, the parasitic electricity $E_{p}$ can be assumed to be a constant 
and further assumed to be zero. The output element $E_{\text {user }}$ can be represented as

$$
\begin{gathered}
E_{u s e r}=\alpha_{u s e r}\left(E_{p g u}+E_{o r c}+E_{g r i d}\right)=\left[\alpha_{u s e r} \alpha_{p g u} \eta_{p g u}\right. \\
+\alpha_{p g u}\left(1-\eta_{p g u}\right) \eta_{h r s} \alpha_{o r c} C O P_{o r c} \alpha_{u s e r} \\
\left.+\alpha_{b} \eta_{b} \alpha_{o r c} \eta_{o r c} \alpha_{u s e r}\right] F_{m}+\alpha_{u s e r} E_{g r i d} .
\end{gathered}
$$

For the cooling part, we have

$$
\begin{aligned}
Q_{c} & =Q_{e c}+Q_{a c}=\alpha_{e c} C O P_{e c}\left(E_{p g u}+E_{o r c}+E_{g r i d}\right) \\
& +\alpha_{a c} C O P_{a c} F_{m}\left[\alpha_{p g u}\left(1-\eta_{p g u}\right) \eta_{h r s}+\alpha_{b} \eta_{b}\right] \\
& =\left[\alpha_{p g u} \eta_{p g u} \alpha_{e c} C O P_{e c}\right. \\
& +\left[\alpha_{p g u}\left(1-\eta_{p g u}\right) \eta_{h r s}+\alpha_{b} \eta_{b}\right] \\
& \cdot \alpha_{o r c} C O P_{o r c} \alpha_{e c} C O P_{e c} \\
& \left.+\left[\alpha_{p g u}\left(1-\eta_{p g u}\right) \eta_{h r s}+\alpha_{b} \eta_{b}\right] \alpha_{a c} C O P_{a c}\right] F_{m} \\
& +\alpha_{e c} C O P_{e c} E_{g r i d} .
\end{aligned}
$$

where the electric cooling to cool load ratio, which is inherently included in the modeling procedure and can be obtained through the optimization, is defined as $e=Q_{e c} / Q_{c}$.

The heating demand is solely provided by the heating unit. Thus, we have

$$
\begin{aligned}
Q_{h} & =\left(Q_{r}+Q_{b}\right) \alpha_{h} \eta_{h} \\
& =\left[\alpha_{p g u}\left(1-\eta_{p g u}\right) \eta_{h r s}+\alpha_{b} \eta_{b}\right] \alpha_{h} \eta_{h} F_{m} .
\end{aligned}
$$

The conversion matrix of the CCHP-ORC system can be obtained from (15)-(17) as

$$
G=\left[\begin{array}{cccc}
0 & 0 & 0 & 0 \\
G_{21} & \alpha_{u s e r} & 0 & 0 \\
G_{31} & \alpha_{e c} C O P_{e c} & 0 & 0 \\
G_{41} & 0 & 0 & 0
\end{array}\right] .
$$

where

$$
\begin{aligned}
G_{21} & =\alpha_{u s e r} \alpha_{p g u} \eta_{p g u}+\alpha_{p g u}\left(1-\eta_{p g u}\right) \\
\cdot & \eta_{h r s} \alpha_{o r c} C O P_{o r c} \alpha_{u s e r}+\alpha_{b} \eta_{b} \alpha_{o r c} \eta_{o r c} \alpha_{u s e r}, \\
G_{31} & =\alpha_{p g u} \eta_{p g u} \alpha_{e c} C O P_{e c} \\
+ & {\left[\alpha_{p g u}\left(1-\eta_{p g u}\right) \eta_{h r s}+\alpha_{b} \eta_{b}\right] } \\
\cdot & \alpha_{o r c} C O P_{o r c} \alpha_{e c} C O P_{e c} \\
+ & {\left[\alpha_{p g u}\left(1-\eta_{p g u}\right) \eta_{h r s}+\alpha_{b} \eta_{b}\right] \alpha_{a c} C O P_{a c}, } \\
G_{41} & =\left[\alpha_{p g u}\left(1-\eta_{p g u}\right) \eta_{h r s}+\alpha_{b} \eta_{b}\right] \alpha_{h} \eta_{h} .
\end{aligned}
$$

The main objective of this paper is to determine the dispatch factors and the system input to optimize the performance criteria objective function.

\section{Optimal Operation Strategy Design}

Having the whole system modeled in a matrix form, we can formulate the operation strategy design as an optimization problem. The objective function and associated constraints will be illustrated in the rest of this section.

3.1. Performance Criteria for the CCHP-ORC System. As mentioned in Section 1. Evaluation of a CCHP system may contain many factors, including primary energy consumption, energy conversion efficiency, total cost of the system, environmental impact, life cycle assessment, and combination of multiple factors. In this paper, three popular criteria, i.e., primary energy consumption, the total cost of the system, and the environmental impact, are adopted to evaluate the performance of the CCHP-ORC system.

3.1.1. Primary Energy Consumption (PEC). PEC is a direct and common indicator to reflect the operating efficiency of a CCHP-ORC system. PEC is defined as

$$
P E C \triangleq \frac{E_{\text {user }}+E_{p}}{\eta_{e} \eta_{\text {grid }}}+\frac{Q_{c}}{C O P_{e c} \eta_{e} \eta_{\text {grid }}}+\frac{Q_{h}}{\eta_{h} \eta_{b}},
$$

where $E_{p}$ is the parasitic electricity, $\eta_{e}$ is the generation efficiency of the grid power plant, and $\eta_{\text {grid }}$ is the transmission efficiency of grid.

3.1.2. Hourly Total Cost (HTC). In order to obtain the optimal energy flow and operation strategy for every hour, HTC is adopted as a key element in the operation strategy optimization. HTC of the CCHP-ORC system is defined as

$$
\begin{aligned}
H T C \triangleq & E_{g r i d} C_{e}+E_{g r i d} \mu_{e} C_{c a}+F_{m} C_{f}+F_{m} \mu_{f} C_{c a} \\
& +\frac{\sum_{k=1}^{l} N_{k} C_{k}}{8760 L}
\end{aligned}
$$

where $C_{e}$ and $C_{f}$ are the unit prices of electricity and the fuel, respectively; $\mu_{e}$ and $\mu_{f}$ are the carbon conversion factors of the the electricity and fuel, respectively; $C_{c a}$ is the carbon tax rate; $N_{k}$ is the installed capacity of each equipment and $C_{k}$ is the initial capital cost of each equipment; $l$ is the number of equipment included in the CCHP-ORC system; and $L$ is the life of each equipment, where we assume that all equipment have the same life time. 8760 (h) represents the hours number of the whole year.

3.1.3. Carbon Dioxide Emission (CDE). Greenhouse gas emission control is an emerging topic in the CCHP system design. In a CCHP-ORC system equipped with fossil-fuel combustion units, CDE serves as an indicator of environment impacts and can be calculated as

$$
C D E \triangleq E_{\text {grid }} \mu_{e}+F_{m} \mu_{f}
$$

where $\mu_{e}$ and $\mu_{f}$ are the carbon conversion factors of the the electricity and fuel, respectively. 
3.1.4. Performance Evaluation Criteria (EC) Function. To comprehensively evaluate the system performance, we define a performance evaluation criteria (EC) function as a weighted summation of the three above mentioned criteria. The most commonly used way to evaluate the performance of a CCHPORC system is to compare those factors with those of the SP system. Thus, the hourly EC function can be redefined as

$$
E C_{\text {hour }} \triangleq \omega_{1} \frac{P E C}{P E C^{S P}}+\omega_{2} \frac{H T C}{H T C^{S P}}+\omega_{3} \frac{C D E}{C D E^{S P}},
$$

where $\omega_{1}, \omega_{2}$, and $\omega_{3}$ are the weights of PEC, HTC, and CDE, respectively. Three weights satisfy

$$
\begin{aligned}
& \omega_{1}+\omega_{2}+\omega_{3}=1 \\
& 0 \leq \omega_{1}, \omega_{2}, \omega_{3} \leq 1 .
\end{aligned}
$$

$P E C^{S P}, H T C^{S P}$, and $C D E^{S P}$ are PEC, HTC, and CDE of the SP system and can be, respectively, calculated as (20), (21), and (22).

Consequently, the annual EC function can be written as

$$
E C_{\text {annual }} \triangleq \sum_{i=1}^{365} \sum_{j=1}^{24} E C_{\text {hourij }}
$$

where $E C_{\text {hourij }}$ is the hourly $E C$ function value on day $i$ at hour $j$.

3.2. Optimization Problem Formulation. Formulating a complete optimization problem includes determining decision variables, designing objective function, and setting constraints. The whole procedure will be elaborated on this part.

3.2.1. Decision Variables. As mention in Section 2, dispatch factors and energy inputs are the variables that need to be adjusted to coordinate the energy flow of the system, meet the building demand, and minimize the objective function. Thus, the dispatch factors and system energy inputs can be selected as decision variables.

It can be readily observed from $(7 \mathrm{a}),(7 \mathrm{~b}),(7 \mathrm{c}),(7 \mathrm{~d})$ and (11a), (11b), (11c), (11d) that the dispatch factors $\alpha_{p g u}, \alpha_{b}$, $\alpha_{\text {user }}, \alpha_{e c}, \alpha_{a c}, \alpha_{\text {orc }}$, and $\alpha_{h}$ are dependent variables. Thus, the dispatch factors can be reduced to be $\alpha_{p g u}, \alpha_{u s e r}, \alpha_{a c}$, and $\alpha_{o r c}$, which are independent of each other.

The system energy inputs include $F_{m}$ and $E_{\text {grid }}$. Thus, the optimizer consisting of all the above-mentioned decision variables can be defined as

$$
x=\left[\begin{array}{llllll}
\alpha_{p g u} & \alpha_{u s e r} & \alpha_{a c} & \alpha_{o r c} & F_{m} & E_{g r i d}
\end{array}\right]^{\top} .
$$

3.2.2. Objective Function. By using the defined optimizer $x$, the $E C_{\text {hour }}$ function in (23) can be written as a linear function of the optimizer $x$ as

$$
E C_{\text {hour }}(x)=\omega_{1} \frac{B x}{P E C^{S P}}+\omega_{2} \frac{C x+L}{H T C^{S P}}+\omega_{3} \frac{D x}{C D E^{S P}} .
$$

where

$$
B=\left[\begin{array}{llllll}
0 & 0 & 0 & 0 & 1 & \frac{1}{\left(\eta_{e}^{S P} \eta_{\text {grid }}\right)}
\end{array}\right]
$$

$$
\begin{aligned}
& C=\left[\begin{array}{llllll}
0 & 0 & 0 & 0 & C_{f}+\mu_{f} C_{c a} & C_{e}+\mu_{e} C_{e}
\end{array}\right], \\
& D=\left[\begin{array}{llllll}
0 & 0 & 0 & 0 & \mu_{f} & \mu_{e}
\end{array}\right] \text {, } \\
& L=\frac{\sum_{k=1}^{l} N_{k} C_{k}}{8760 L} \text {. }
\end{aligned}
$$

$E C_{\text {hour }}(x)$ will serve as the objective function of the optimization-based operation strategy design. $\omega_{1}, \omega_{2}$, and $\omega_{3}$ can be set according to different evaluation requirements. For example, $\omega_{3}$ would be set relatively higher if more emphases are put on the environmental aspect.

3.2.3. Equality Constraint. In the sense of balance, (14) will serve as the equality constraint of the optimization problem. Further, since some elements in $G$ are represented by the decision variables, it is necessary to write $G$ as a function of $x$. Thus we have

$$
\begin{aligned}
G & =\left(g_{211} W_{22}+g_{311} W_{33}+g_{313} W_{32}+g_{315} W_{34}\right. \\
& \left.-g_{411} W_{43}\right) x x^{\top} U_{11}+\left(g_{312} W_{33}+g_{314} W_{31}\right. \\
& \left.+g_{316} W_{34}+g_{411} W_{41}-g_{412} W_{43}\right) x Q_{11}+\left(g_{212} W_{22}\right. \\
& \left.-g_{316} W_{32}+g_{213} W_{22}\left(x^{\top} Q_{1}\right)-g_{315} W_{32}\left(x^{\top} Q_{1}\right)\right) \\
& \cdot x x^{\top} U_{41}+\left(g_{221} W_{22}-g_{321} W_{32}\right) x Q_{12} \\
& +\left(C_{c_{c o p}}+C O N_{\eta_{h} \eta_{b}}\right)
\end{aligned}
$$

where

$$
\begin{aligned}
& W_{22}=\left[\begin{array}{llllll}
0 & 0 & 0 & 0 & 0 & 0 \\
0 & 1 & 0 & 0 & 0 & 0 \\
0 & 0 & 0 & 0 & 0 & 0 \\
0 & 0 & 0 & 0 & 0 & 0
\end{array}\right], \\
& W_{31}=\left[\begin{array}{llllll}
0 & 0 & 0 & 0 & 0 & 0 \\
0 & 0 & 0 & 0 & 0 & 0 \\
1 & 0 & 0 & 0 & 0 & 0 \\
0 & 0 & 0 & 0 & 0 & 0
\end{array}\right], \\
& W_{32}=\left[\begin{array}{llllll}
0 & 0 & 0 & 0 & 0 & 0 \\
0 & 0 & 0 & 0 & 0 & 0 \\
0 & 1 & 0 & 0 & 0 & 0 \\
0 & 0 & 0 & 0 & 0 & 0
\end{array}\right], \\
& W_{33}=\left[\begin{array}{llllll}
0 & 0 & 0 & 0 & 0 & 0 \\
0 & 0 & 0 & 0 & 0 & 0 \\
0 & 0 & 1 & 0 & 0 & 0 \\
0 & 0 & 0 & 0 & 0 & 0
\end{array}\right],
\end{aligned}
$$




$$
\begin{array}{rlrl}
W_{41} & =\left[\begin{array}{llllll}
0 & 0 & 0 & 0 & 0 & 0 \\
0 & 0 & 0 & 0 & 0 & 0 \\
0 & 0 & 0 & 0 & 0 & 0 \\
1 & 0 & 0 & 0 & 0 & 0
\end{array}\right], & g_{313}=-\eta_{p g u} C O P_{e c}, \\
W_{43}=\left[\begin{array}{llllll}
0 & 0 & 0 & 0 & 0 & 0 \\
0 & 0 & 0 & 0 & 0 & 0 \\
0 & 0 & 0 & 0 & 0 & 0 \\
0 & 0 & 1 & 0 & 0 & 0
\end{array}\right], & g_{321}=-C O P_{e c}, \\
g_{314}=\eta_{p g u} C O P_{e c}, \\
Q_{11}=\left[\begin{array}{llll}
1 & 0 & 0 & 0
\end{array}\right], & g_{412}=\eta_{h} \eta_{b}, \\
Q_{12}=\left[\begin{array}{llll}
0 & 1 & 0 & 0
\end{array}\right], & g_{316}=\eta_{b} C O P_{o r c} C O P_{e c}, \\
\end{array}
$$$$
Q_{1}=\left[\begin{array}{llllll}
1 & 0 & 0 & 0 & 0 & 0
\end{array}\right]^{\top},
$$$$
U_{11}=\left[\begin{array}{llll}
1 & 0 & 0 & 0 \\
0 & 0 & 0 & 0 \\
0 & 0 & 0 & 0 \\
0 & 0 & 0 & 0 \\
0 & 0 & 0 & 0 \\
0 & 0 & 0 & 0
\end{array}\right],
$$$$
U_{41}=\left[\begin{array}{llll}
0 & 0 & 0 & 0 \\
0 & 0 & 0 & 0 \\
0 & 0 & 0 & 0 \\
1 & 0 & 0 & 0 \\
0 & 0 & 0 & 0 \\
0 & 0 & 0 & 0
\end{array}\right],
$$$$
\mathrm{CON}_{\mathrm{COP} P_{e c}}=\left[\begin{array}{cccc}
1 & 0 & 0 & 0 \\
0 & 0 & 0 & 0 \\
0 & C O P_{e c} & 0 & 0 \\
0 & 0 & 0 & 0
\end{array}\right] \text {, }
$$$$
\operatorname{CON}_{\eta_{h} \eta_{b}}=\left[\begin{array}{cccc}
0 & 0 & 0 & 0 \\
0 & 0 & 0 & 0 \\
0 & 0 & 0 & 0 \\
\eta_{h} \eta_{b} & 0 & 0 & 0
\end{array}\right] \text {, }
$$

and

$$
\begin{aligned}
& g_{211}=\eta_{p g u}, \\
& g_{221}=1, \\
& g_{212}=\eta_{b} C O P_{\text {orc }}, \\
& g_{213}=\left(\left(1-\eta_{p g u}\right) \eta_{h r s}-\eta_{b}\right) C O P_{\text {orc }}, \\
& g_{312}=\eta_{b} C O P_{a c},
\end{aligned}
$$

Similarly, the system input $V_{i}$ should also be represented by $x$ as

$$
V_{i}=P x,
$$

where

$$
P=\left[\begin{array}{llllll}
0 & 0 & 0 & 0 & 1 & 0 \\
0 & 0 & 0 & 0 & 0 & 1 \\
0 & 0 & 0 & 0 & 0 & 0 \\
0 & 0 & 0 & 0 & 0 & 0
\end{array}\right] .
$$

Then the nonlinear equality constraint in (14) becomes

$$
\begin{aligned}
& \left(g_{211} W_{22}+g_{311} W_{33}+g_{313} W_{32}+g_{315} W_{34}-g_{411} W_{43}\right) \\
& \cdot x x^{\top} U_{11} P x+\left(g_{312} W_{33}+g_{314} W_{31}+g_{316} W_{34}\right. \\
& \left.+g_{411} W_{41}-g_{412} W_{43}\right) x Q_{11} P x+\left(g_{212} W_{22}\right. \\
& \left.-g_{316} W_{32}+\left(g_{213} W_{22}-g_{315} W_{32}\right)\left(x^{\top} Q_{1}\right)\right) \\
& \cdot x x^{\top} U_{41} P x+\left(g_{221} W_{22}+g_{321} W_{32}\right) x Q_{12} P x \\
& +\left(C O N_{c o p_{e c}}+C O N_{\eta_{h} \eta_{b}}\right) P x-V_{o}=0 .
\end{aligned}
$$

3.2.4. Inequality Constraints. The inequality constraints include the bound of the decision variables, various capacities of system components, and thresholds of the components output. The decision variables can be separated into two parts: one consists of dispatch factors, and the other consists of system input. To facilitate the later derivation, we define $\boldsymbol{\alpha}$ dispatch factor vector as

$$
\boldsymbol{\alpha}=\left[\begin{array}{llll}
\alpha_{p g u} & \alpha_{u s e r} & \alpha_{a c} & \alpha_{\text {orc }}
\end{array}\right]^{\top} .
$$

According to (7a), (7b), (7c), (7d) and (11a), (11b), (11c), (1ld), we have

$$
\begin{array}{r}
-\boldsymbol{\alpha} \leq \mathbf{0}, \\
\boldsymbol{\alpha}-\mathbf{1} \leq \mathbf{0} .
\end{array}
$$


In this paper, we assume that no electricity would be sold back; thus the constraints for fuel and electricity input can be represented by

$$
\begin{aligned}
\boldsymbol{\beta} & =\left[\begin{array}{ll}
F_{m} & E_{\text {grid }}
\end{array}\right]^{\top} . \\
-\boldsymbol{\beta} & \leq \mathbf{0} .
\end{aligned}
$$

Inequalities in (36a), (36b), and (38) are linear inequality constraints seeing as the bounds of the decision variables.

Each component in the CCHP-ORC system has a specific capacity, which is the output upper bound. Denote $F_{\text {orcm }}$ the capacity of ORC; then the upper bound of the ORC output can be represented as

$$
\bar{V}_{o}^{o r c}=\left[\begin{array}{c}
0 \\
\bar{E}_{o}^{o r c} \\
0 \\
0
\end{array}\right]=\left[\begin{array}{c}
0 \\
F_{\text {orcm }} C O P_{\text {orc }} \\
0 \\
0
\end{array}\right] .
$$

The output upper bound of the PGU, heat recovery system, auxiliary boiler, electric chiller, absorption chiller, and heating unit can be denoted as $\bar{V}_{o}^{p g u}, \bar{V}_{o}^{h r s}, \bar{V}_{o}^{b}, \bar{V}_{o}^{e c}, \bar{V}_{o}^{a c}$, and $\bar{V}_{o}^{h}$ and defined in a similar way as in (39), respectively.

In addition, the lower bound of the ORC, PGU, heat recovery system, auxiliary boiler, electric chiller, absorption chiller, and heating unit can be denoted as $V_{o}^{\text {orc }}, \underline{V}_{0}^{p g u}, \underline{V}_{0}^{h r s}$, $\underline{V}_{0}^{b}, \underline{V}_{0}^{e c}, \underline{V}_{o}^{a c}$, and $\underline{V}_{0}^{h}$. The lower bound of a component implies that the output will be cut down when the expected output of the component is lower than this bound. In this paper, the lower bound can be set as 5 percent of the maximum capacity of each component.

Based on the above discussions, the bounding conditions for component output can be represented by

$$
\begin{aligned}
H^{m} V_{i}^{m}-\bar{V}_{o}^{m} & \leq 0, \\
\underline{V}_{o}^{m}-H^{m} V_{i}^{l} & \leq 0 .
\end{aligned}
$$

Then from (9) and (32), (40a), (40b) can be rewritten as

$$
\begin{aligned}
& H^{m} T_{m} P x-\bar{V}_{o}^{m} \leq 0, \\
& \underline{V}_{o}^{m}-H^{m} T_{m} P x \leq 0,
\end{aligned}
$$

where $T_{m}$ is the dispatch matrix for the component $m$ in the CCHP-ORC system and can also be represented by the function of $x$ by following the similar procedure of deriving (29) as

$$
\begin{aligned}
T_{p g u} & =W_{11} x Q_{11}, \\
T_{b} & =I_{11}-W_{11} x Q_{11}, \\
T_{h r s} & =\delta_{1} W_{41} x Q_{11}, \\
T_{e c} & =I_{22}-W_{22} x Q_{12}, \\
T_{a c} & =\delta_{2} W_{43} x x^{T} U_{11}+\delta_{3} W_{43} x Q_{11},
\end{aligned}
$$

$$
\begin{aligned}
T_{h}= & -\delta_{2} W_{43} x x^{T} U_{11}+\left(\delta_{2} W_{41}-\delta_{3} W_{43}\right) x Q_{11} \\
& +C O N_{\eta_{b}}, \\
T_{\text {orc }}= & \delta_{2} W_{44} x x^{T} U_{11}+\delta_{3} W_{44} x Q_{11},
\end{aligned}
$$

where

$$
\begin{aligned}
W_{11} & =\left[\begin{array}{llllll}
1 & 0 & 0 & 0 & 0 & 0 \\
0 & 0 & 0 & 0 & 0 & 0 \\
0 & 0 & 0 & 0 & 0 & 0 \\
0 & 0 & 0 & 0 & 0 & 0
\end{array}\right], \\
W_{44} & =\left[\begin{array}{llllll}
0 & 0 & 0 & 0 & 0 & 0 \\
0 & 0 & 0 & 0 & 0 & 0 \\
0 & 0 & 0 & 0 & 0 & 0 \\
0 & 0 & 0 & 1 & 0 & 0
\end{array}\right], \\
I_{11} & =\left[\begin{array}{llll}
1 & 0 & 0 & 0 \\
0 & 0 & 0 & 0 \\
0 & 0 & 0 & 0 \\
0 & 0 & 0 & 0
\end{array}\right], \\
I_{22} & =\left[\begin{array}{llll}
0 & 0 & 0 & 0 \\
0 & 1 & 0 & 0 \\
0 & 0 & 0 & 0 \\
0 & 0 & 0 & 0
\end{array}\right], \\
\operatorname{CON}_{\eta_{b}}= & {\left[\begin{array}{llll}
0 & 0 & 0 & 0 \\
0 & 0 & 0 & 0 \\
0 & 0 & 0 & 0 \\
\eta_{b} & 0 & 0 & 0
\end{array}\right], }
\end{aligned}
$$

and $\delta_{1}=1-\eta_{p g u}, \delta_{2}=g_{411} / \eta_{h}$, and $\delta_{3}=g_{412} / \eta_{h}$.

Therefore, (36a), (36b), and (38) are the linear inequality constraints, and (41a) and (41b) are the nonlinear inequality constraint of the optimization problem. The optimal solution can be obtained by solving

$$
\begin{array}{ll}
\min _{x} & \omega_{1} \frac{B x}{P E C^{S P}}+\omega_{2} \frac{C x+L}{H T C^{S P}}+\omega_{3} \frac{D x}{C D E^{S P}} \\
\text { s.t. } & (34),(36 a),(36 b),(38),(41 a), \text { and }(41 b) .
\end{array}
$$

The objective function integrates three aspects, i.e., PEC, HTC, and CDE, into it, and it is comprehensive. Three weights $\omega_{1}, \omega_{2}$, and $\omega_{3}$, can be selected according to different requirements. For example, if more priority is need to be given to environmental factors, the carbon dioxide emission (CDE) should be put on more emphasis, then $\omega_{3}$ is raised, and $\omega_{1}$ and $\omega_{2}$ are accordingly decreased. 
TABLE 1: Construction parameters of the office building.

\begin{tabular}{lc}
\hline Parameters & Values \\
\hline Each floor area & $1200 \mathrm{~m}^{2}(30 \mathrm{~m} \times 40 \mathrm{~m})$ \\
\hline Each floor height & $3.2 \mathrm{~m}$ \\
\hline Glass area & $38 \%$ in each wall \\
\hline Glazing heat transfer coefficient & $4.128 \mathrm{~W} /\left(\mathrm{m}^{2} \mathrm{~K}\right)$ \\
\hline Exterior wall heat transfer coefficient & $0.440 \mathrm{~W} /\left(\mathrm{m}^{2} \mathrm{~K}\right)$ \\
\hline Interior wall heat transfer coefficient & $0.716 \mathrm{~W} /\left(\mathrm{m}^{2} \mathrm{~K}\right)$ \\
\hline Floor heat transfer coefficient & $2.300 \mathrm{~W} /\left(\mathrm{m}^{2} \mathrm{~K}\right)$ \\
\hline Roof heat transfer coefficient & $0.368 \mathrm{~W} /\left(\mathrm{m}^{2} \mathrm{~K}\right)$ \\
\hline Electric equipment, lights, and people densities & According to Wuhan's energy-saving design standard \\
\hline
\end{tabular}

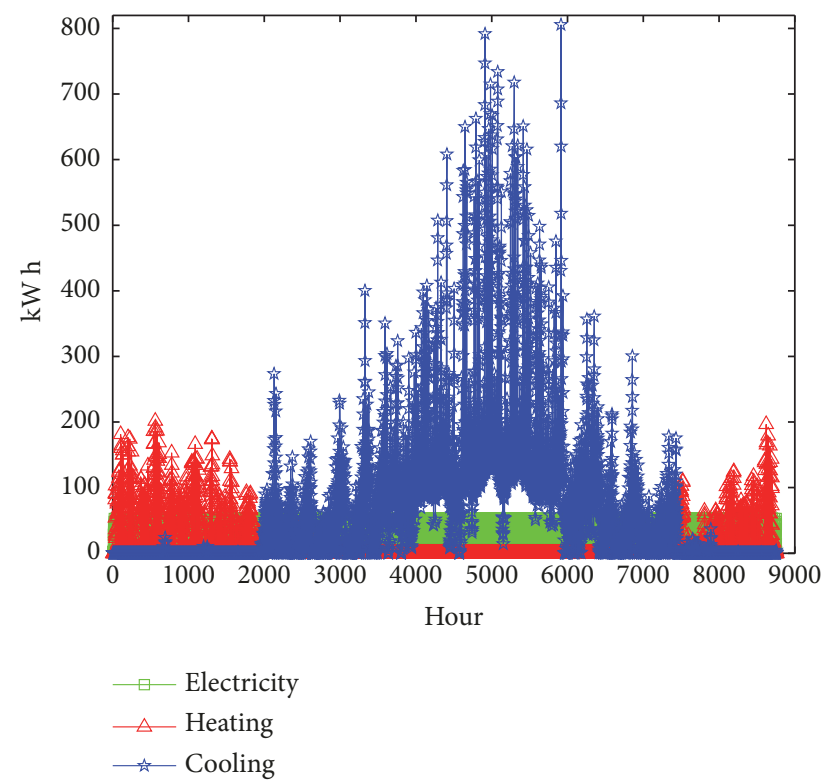

FIgURE 2: One-year energy consumption.

\section{Case Study}

4.1. Description of a Hypothetical Building. In this section, a CCHP-ORC system is installed for a hypothetical office building in Wuhan, Hubei, China, because the CCHP-ORC system is more suitable to the commercial building and the office building with low ratio of heat to power demand [35]. We chose EnergyPlus [38,39] to analyze energy consumption of this building. This building is assumed to operate all year round and has five floors with a total construction area of $6000 \mathrm{~m}^{2}$. The first floor consists of $400 \mathrm{~m}^{2}$ exhibition halls and $800 \mathrm{~m}^{2}$ office rooms. The second to the fifth floors are office rooms. Some important construction parameters of the hypothetical office building are listed in Table 1.

The hourly cooling, heating, and power requirements in one year of the hypothetical office building are shown in Figure 2.

To ease the performance comparison, the hourly cooling, heating, and power requirements in representative days of spring, summer, autumn, and winter are shown in Figures $3-6$, respectively.

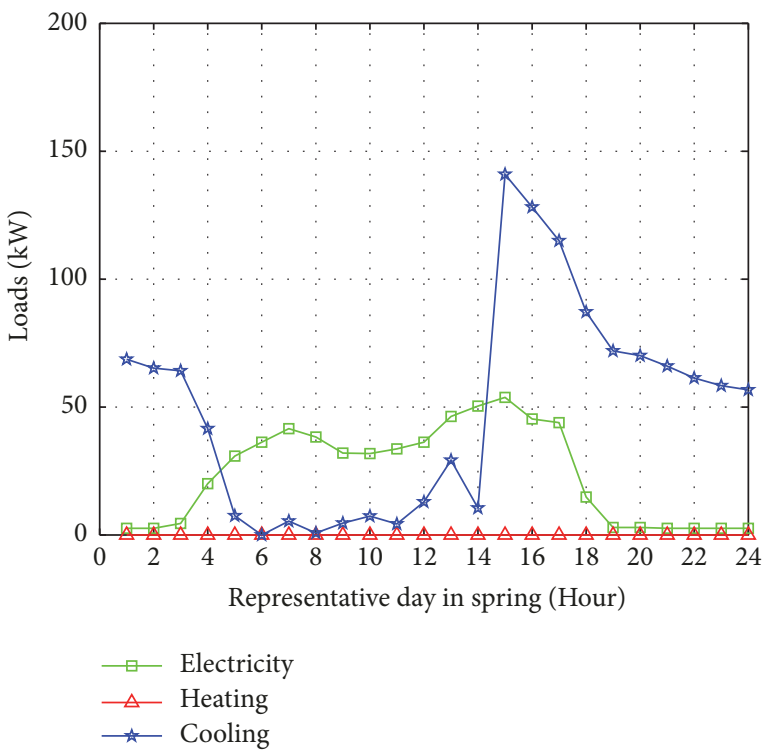

FIGURE 3: Hourly energy requirements in a spring day.

From Figures 2-6, it can be noticed that the cooling requirements in summer are the most, the heating requirements in winter are more than those of other seasons, and the electricity requirements are substantially the same for each season.

4.2. Simulation Parameters. Table 2 shows a set of technical parameters of the installed CCHP-ORC system for the hypothetical building. In this paper, the fuel is the natural gas which is widely used in China. The gas turbine is chosen as PGU. For performance comparison, some parameters of a conventional CCHP system, coefficient of performance, and efficiency of the components in the CCHP-ORC system, conversion factors, and weight factors are included in Table 2. The weighting factors of the evaluation criteria can be chosen to satisfy different requirements. Some parameters listed in Table 2 fluctuate with the market, such as price of electricity, natural gas, and carbon tax. Most of the system parameters can be gotten from equipment manual and some references. 
TABLE 2: System coefficients.

\begin{tabular}{|c|c|c|}
\hline Symbol & Variable & Value \\
\hline$\eta_{p g u}$ & Efficiency of PGU in CCHP-ORC system & 0.35 \\
\hline$\eta_{e}^{S P}$ & Generation efficiency SP system & 0.40 \\
\hline$\overline{\eta_{h}}$ & Efficiency of heating unit & 0.78 \\
\hline$\eta_{b}$ & Efficiency of auxiliary boiler & 0.78 \\
\hline$\eta_{h r s}$ & Efficiency of heat recovery system & 0.81 \\
\hline$C O P_{\text {orc }}$ & Coefficient of performance of ORC & 0.17 \\
\hline$C O P_{a c}$ & Coefficient of performance of absorption chiller & 0.72 \\
\hline$C O P_{e c}$ & Coefficient of performance of electric chiller & 2.98 \\
\hline$\eta_{\text {grid }}$ & Transmission efficiency of local grid & 0.92 \\
\hline$\mu_{e}$ & $\mathrm{CO}_{2}$ emission conversion factor of electricity $(\mathrm{g} / \mathrm{kW} \mathrm{h})$ & 970 \\
\hline$\mu_{f}$ & $\mathrm{CO}_{2}$ emission conversion factor of natural gas $(\mathrm{g} / \mathrm{kW} \mathrm{h})$ & 218 \\
\hline$C_{c}$ & Carbon tax rates (yuan/kW h) & 0.00002 \\
\hline$\overline{C_{e}}$ & Electricity rates (yuan/kW h) & 0.642 \\
\hline$C_{f}$ & Natural gas rates (yuan/kW h) & 0.375 \\
\hline$C_{p g u}$ & Unit price of PGU (yuan/kW h) & 6800 \\
\hline$C_{b}$ & Unit price of auxiliary boiler (yuan $/ \mathrm{kW} \mathrm{h}$ ) & 300 \\
\hline$C_{h}$ & Unit price of heating unit (yuan/kW h) & 200 \\
\hline$C_{a c}$ & Unit price of absorption chiller (yuan/kW h) & 1200 \\
\hline$C_{e c}$ & Unit price of electric chiller (yuan/kW h) & 970 \\
\hline$C_{\text {orc }}$ & Unit price of ORC (yuan/kW ) & 12000 \\
\hline$L$ & Facilities' lives (year) & 20 \\
\hline$\omega_{1}$ & Coefficient of PEC & 0.6 \\
\hline$\omega_{2}$ & Coefficient of HTC & 0.3 \\
\hline$\omega_{3}$ & Coefficient of CDE & 0.1 \\
\hline
\end{tabular}

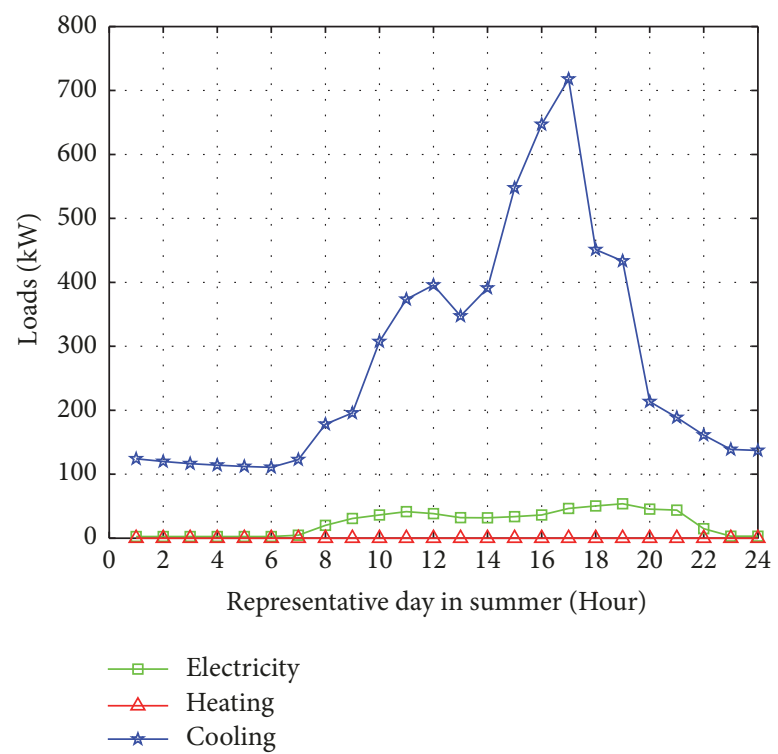

FIGURE 4: Hourly energy requirements in a summer day.

4.3. Test Result. SQP algorithms have been proved highly effective for solving general constrained problems with smooth objective and constraint functions [40]. In this paper, we chose SQP algorithms to solve the optimization

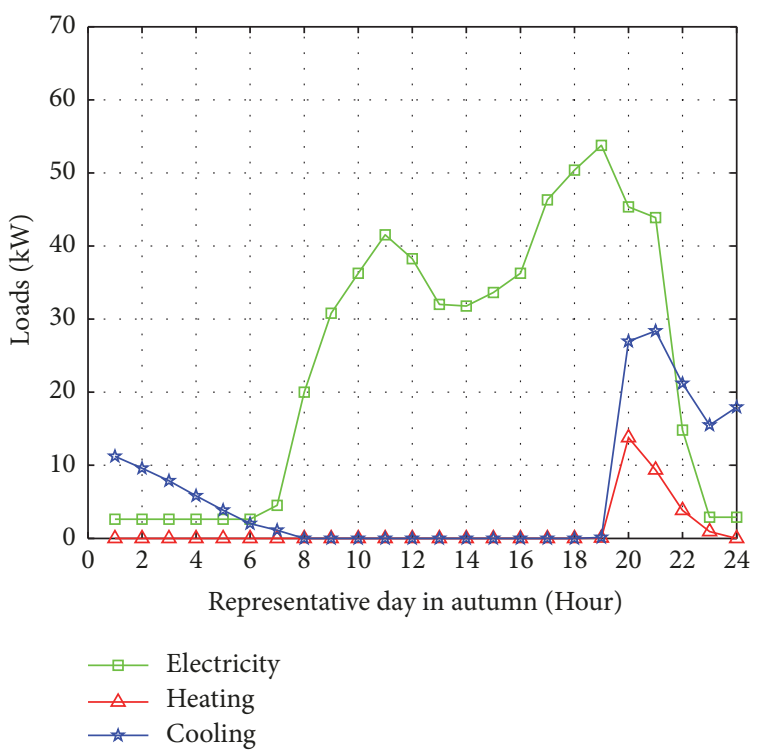

FIGURE 5: Hourly energy requirements in a autumn day.

problem established in Section 3.2. In order to accelerate the convergence, some feasible initial points which are calculated from FEL and FTL strategies are manually designated. So the 


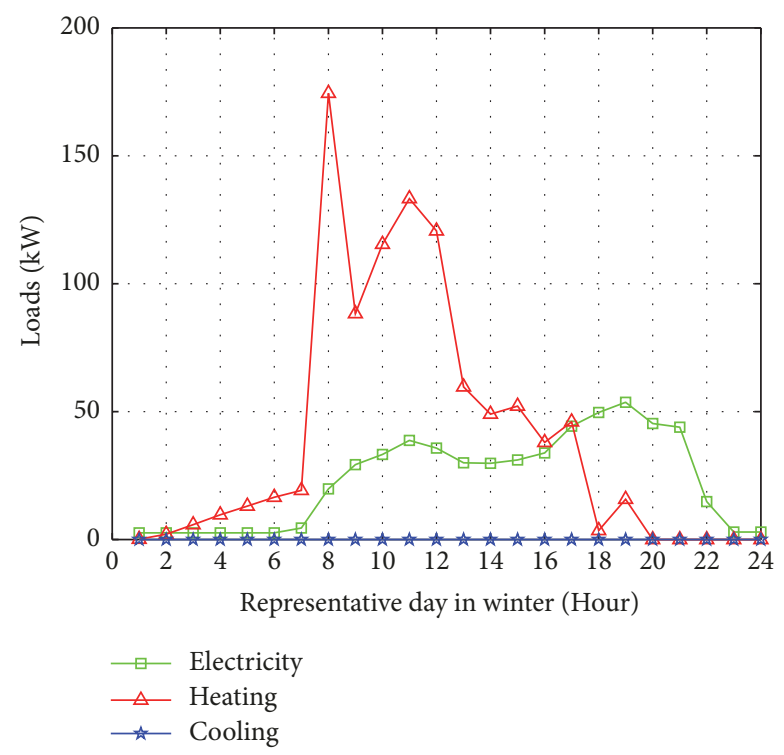

FIgURE 6: Hourly energy requirements in a winter day.

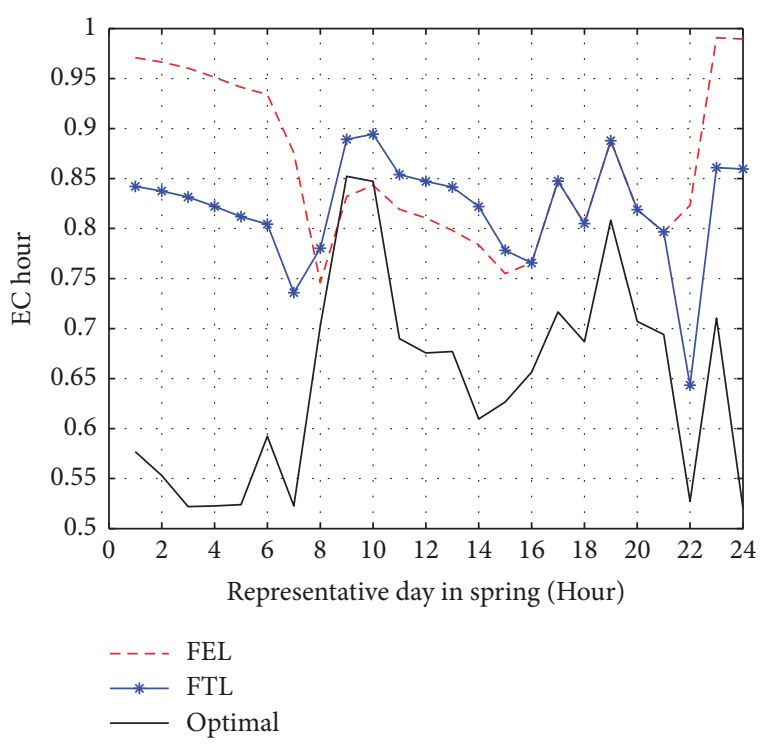

FIGURE 7: Comparison of three strategies in a spring day.

local optimal solution can be avoided and the convergence time is significantly reduced.

The constructed optimization problem is solved in MATLAB by using fmincon.m. The computer used to solve this problem is configured with $2.6 \mathrm{GHz}$ Intel Core i5-3230M processor and $4 \mathrm{~GB} 1067 \mathrm{MHz}$ memory. Time elapsed for each step of optimization is about $0.25 \mathrm{~s}$. This time is much shorter than one hour; in other words, the optimal energy flow and operation strategy for the next hour can be quickly obtained at the beginning of this hour. Thus, we can say that the optimization method is appropriate for practical use.

The performance comparison of FEL, FTL, and the proposed optimal operation strategy is shown in Figures 7-10 which includes spring, summer, autumn, and winter,

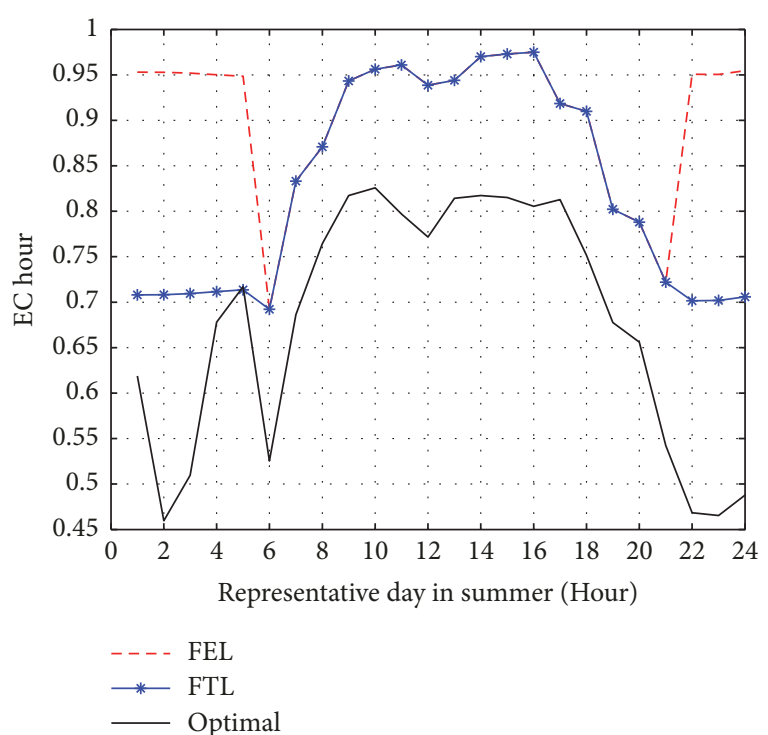

FIGURE 8: Comparison of three strategies in a summer day.

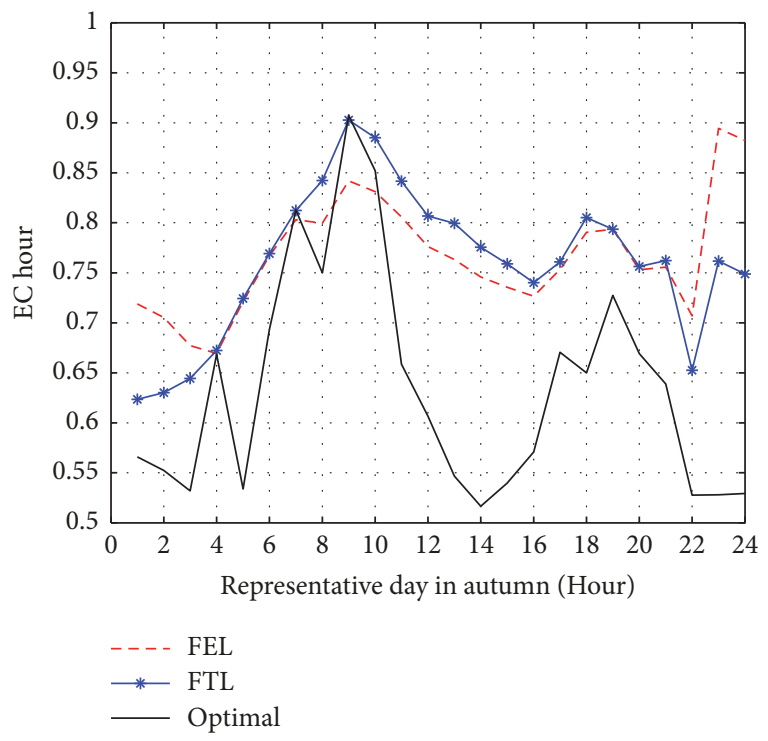

FIGURE 9: Comparison of three strategies in an autumn day.

respectively. From Figures 8 and 10, all $E C_{\text {hour }}$ values of the optimal operation strategy are obviously less than those of the FEL and FTL strategies. From Figures 7 and 9, most $E C_{\text {hour }}$ values are also obviously less than those of FEL and FTL except 8:00-10:00. Because it is the beginning working time during 8:00-10:00, electricity requirements are very large, and there are almost no heating and cooling requirements. Taking into account the full day values, the performance of the optimal operation strategy is much better than that of FEL and FTL strategies. In spring, summer, and autumn, especially in the morning and in the evening, the optimal energy flow has excellent performance, while in the middle of a day, the advantage is not that evident. In winter, the performance in the middle of a day is much better than that in the morning and in the evening. 
TABLE 3: Equipment's capacities.

\begin{tabular}{lcccccc}
\hline Items & PGU & ORC & $\begin{array}{c}\text { Auxiliary } \\
\text { boiler }\end{array}$ & $\begin{array}{c}\text { Electric } \\
\text { chiller }\end{array}$ & $\begin{array}{c}\text { Absorption } \\
\text { chiller }\end{array}$ & $\begin{array}{c}\text { Heating } \\
\text { coil }\end{array}$ \\
\hline CCHP $(\mathrm{kW})$ & 100 & - & 200 & 450 & 450 & 220 \\
\hline CCHP-ORC $(\mathrm{kW})$ & 80 & 20 & 100 & 450 & 450 & 220 \\
\hline
\end{tabular}

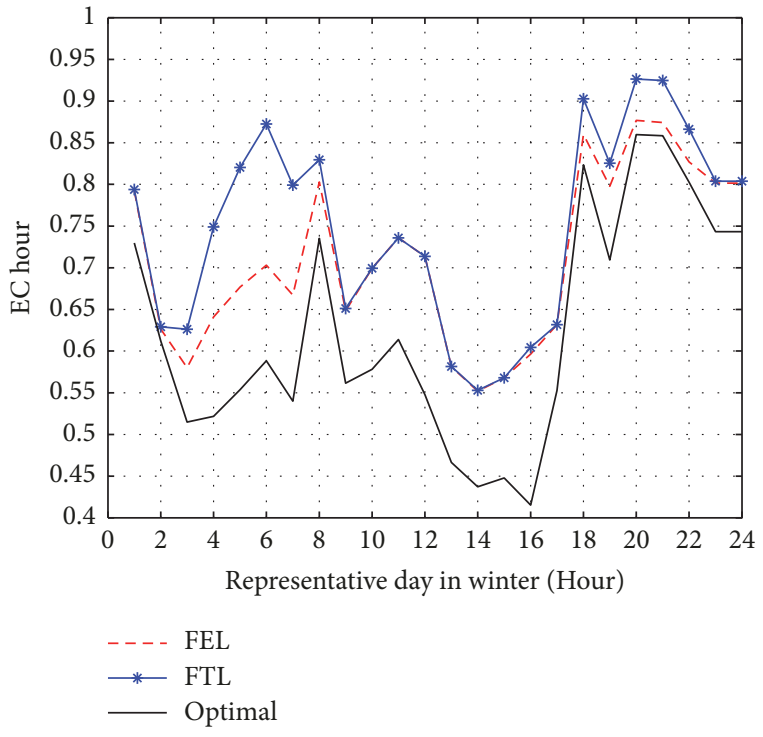

FIgURE 10: Comparison of three strategies in a winter day.

The reason for the proposed optimal operation strategy performing better than FEL and FTL strategies is that both FEL and FTL strategies are inevitably wasting energy. When operating at FEL mode, electricity for the building is firstly satisfied, and then if the thermal energy provided by PGU cannot meet the thermal demand, the auxiliary boiler will be activated; if the thermal supply exceeds the thermal demand, the excess thermal energy will be wasted. When operating at FTL mode, the thermal requirements are firstly satisfied, and then if the electricity provided by PGU cannot meet the electricity demand, additional electricity should be purchased from the power grid; if the electricity provided by PGU is sufficient, a certain amount of electricity will be wasted.

The CCHP-ORC system includes ORC component as a power generator to make full use of excess thermal energy, and its integration with CCHP system has good application prospects. According to the energy requirements in representative days shown in Figures 3-6, the hourly outputs of the electric chiller and the ORC in representative days can be calculated as Figures 11-14.

From Figures 11-14, we can find that the electric chiller has high utilization rate in summer because of the high temperature in Wuhan, and the ORC plays a significant role in other three seasons.

Substituting the primary energy consumptions, the daily total cost, and the carbon dioxide emission into (20)-(22), the daily performance criteria (i.e., PEC, DTC, CDE) for

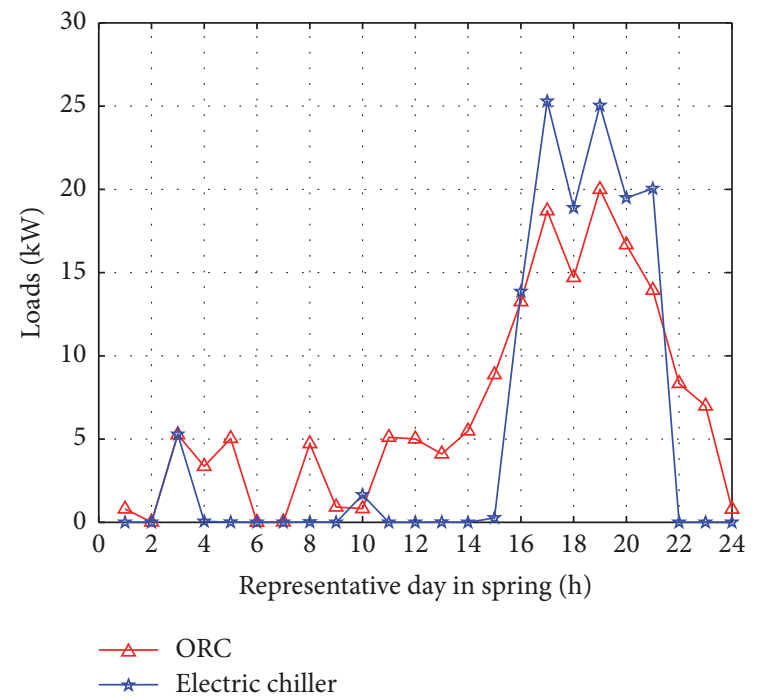

FIGURE 11: Hourly outputs of the EC and ORC in a spring day.

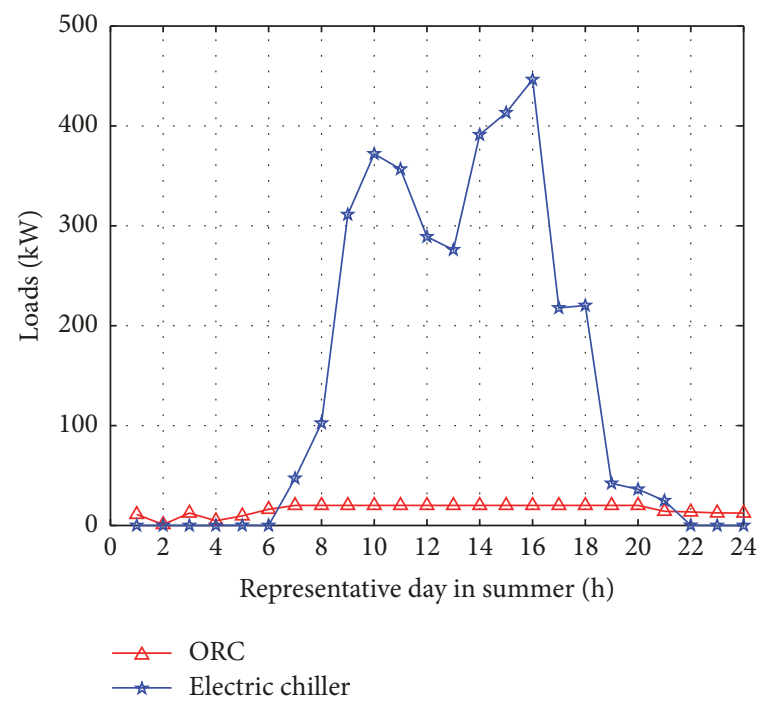

FIGURE 12: Hourly outputs of the EC and ORC in a summer day.

the CCHP-ORC and the CCHP system can be calculated. Capacities of all equipment in the CCHP-ORC and CCHP system are listed in Table 3.

In Table 3, the capacity of PGU in the CCHP system is $100 \mathrm{~kW}$, which is searched in $[1,500]$ with the whole year (8760h) data using enumeration algorithm. In the CCHPORC system, ORC is combined as power generator. In order to satisfy the power requirements, the sum capacity of PGU and ORC should be equal $100 \mathrm{~kW}$ which is the optimal 
TABLE 4: Performance comparisons of the CCHP-ORC system and the CCHP system.

\begin{tabular}{lcccccc}
\hline \multirow{2}{*}{ Representative days } & \multicolumn{2}{c}{ PEC(kWh) } & \multicolumn{2}{c}{ DTC(Yuan) } & \multicolumn{2}{c}{ CDE(g) } \\
& CCHP & CCHP-ORC & CCHP & CCHP-ORC & CCHP & CCHP-ORC \\
\hline Spring day & 3374.1 & 3230.9 & 1021.2 & 992.5 & 821740.0 & 790230.0 \\
\hline Summer day & 11909.0 & 11455.0 & 3077.7 & 2986.7 & 2956700.0 & 2856900.0 \\
\hline Autumn day & 2247.1 & 2214.3 & 762.5 & 758.3 & 548660.0 & 543260.0 \\
\hline Winter day & 2626.3 & 2618.6 & 869.9 & 817.0 & 648430.0 & 607230.0 \\
\hline
\end{tabular}

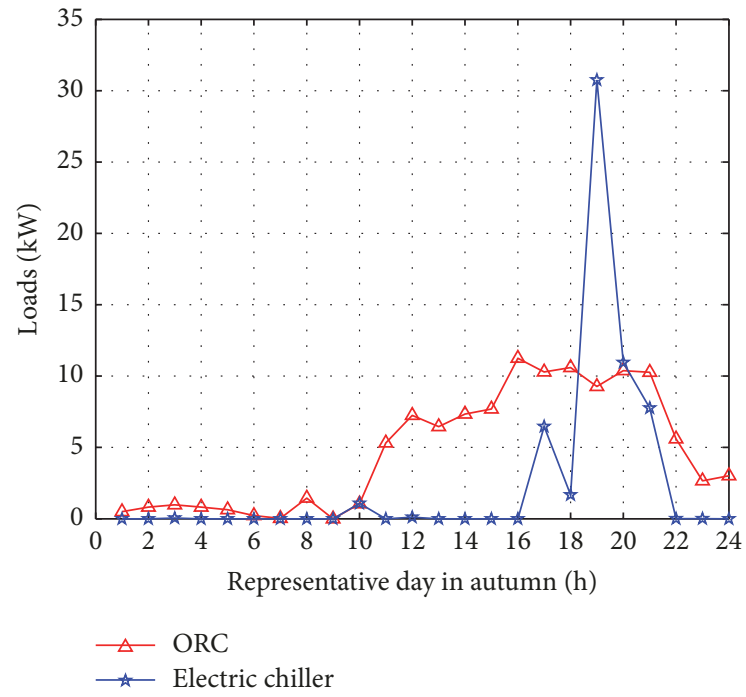

FIGURE 13: Hourly outputs of the EC and ORC in an autumn day.

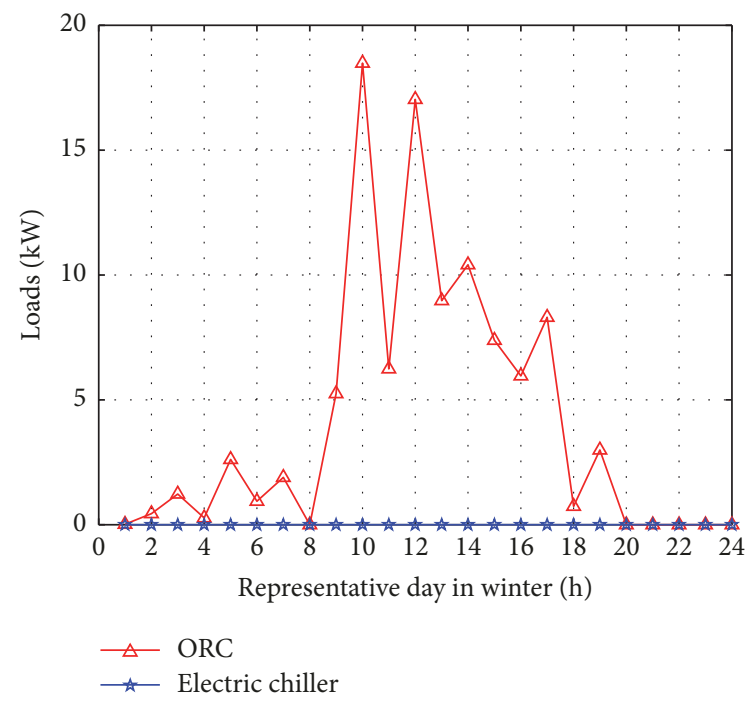

FIGURE 14: Hourly outputs of the EC and ORC in a winter day.

capacity in the CCHP system. In addition, efficiency of PGU is higher than that of the ORC. For the office building with low ratio of heat to power demand, power requirements are more than other requirements, so the capacity of PGU should be far larger than that of ORC. Through enumeration, the optimal capacity of PGU and ORC is $80 \mathrm{~kW}$ and $20 \mathrm{~kW}$, respectively.
The performance comparisons of the CCHP-ORC system and the CCHP system are shown in Table 4. It is clear that all the performance values of the CCHP-ORC system are smaller than those of the CCHP system and the performances of the CCHP-ORC system are better than those of the CCHP system. The integration of ORC and PGU can improve the energy efficiency and reduce the capacity requirements of the auxiliary boiler and PGU. With the reduction of the ORC's price, the superiority of the CCHP-ORC system will be more and more outstanding.

If we assume that the price of ORC is about 100000 Yuan, from Table 4, we only consider the PEC and DTC, we can find the whole year's PEC saving is 58190.13 Yuan, the total consumption reduction is 16123.88 Yuan, and the sum of the whole year's PEC saving and the total consumption reduction is 74314 Yuan. So the CCHP-ORC system runs 1 year and 4 months, and the cost of ORC is recovered.

\section{Conclusion}

A complementary configuration of the CCHP-ORC system is investigated to further improve the utilization efficiency of the excess thermal energy from the CCHP system. A comprehensive and systematic matrix modeling approach is proposed to describe the CCHP-ORC system. The matrix model includes efficiency matrices of system components, system conversion matrix, and dispatch factors. The optimal operation strategy is obtained by solving the optimization problem. Both economic and environmental factors are considered in the objective function of the optimal operation strategy design. The weights of economic and environmental factors can be changed according to different requirements. At last, an illustrative case study is conducted to show that the effectiveness and economic efficiency of the proposed approaches outperform those obtained from conventional CCHP systems.

The main challenges of applying this method to real system are that some uncertainties in the CCHP-ORC system exist; for example, a likely source of uncertainty in the heat exchanger components of the CCHP-ORC system is fouling. The efficiencies of heat exchanger components are changed. In real system, we should consider these uncertainties by adding an error of less than $5 \%$ of the nominal value of the parameters.

The main problem of the CCHP-ORC system is high investment cost of the ORC. However the unit price of the ORC will continually decline because of the technology maturing in recent years. Therefore the CCHP-ORC system 
will be more attractive and valuable. In addition, all calculation in this paper is based on an accurate load profile. While, in practical applications, accurate load profile does not exist, therefore, in future work, accurate load forecasting should be considered. In a further step, excess electricity sold back feature can be considered. In recent years, with the development of the renewable energy including solar energy, wind energy, and tide energy, more and more renewable energy should be incorporated into the CCHP system to make the trigeneration system more efficient.

\section{Nomenclature}

CCHP: Combined cooling, heating, and power

CDE: Carbon dioxide emission

COP: Coefficient of performance

DTC: Daily total cost

EC: Evaluation criteria

FEL: $\quad$ Following the electric load

FTL: $\quad$ Following the thermal load

HTC: Hourly total cost

ORC: Organic Rankine cycles

PEC: Primary energy consumption

$P G U$ : Power generation unit

$S P: \quad$ Separation production.

Symbols

C: Cost

E: Electricity

F: Fuel

L: Facility life

$N$ : Installed power

$Q$ : Thermal energy

$\eta$ : Efficiency

$\mu$ : Carbon conversion factor.

\section{Subscripts}

$\begin{array}{ll}\text { ac: } & \text { Absorption chiller } \\ \text { annual: } & \text { Annual value } \\ b: & \text { Auxiliary boiler } \\ c: & \text { Cooling } \\ c a: & \text { Carbon } \\ e: & \text { Electricity } \\ e c: & \text { Electric chiller } \\ f: & \text { Fuel } \\ \text { grid: } & \text { Local power grid } \\ h: & \text { Heating } \\ h o u r: & \text { Hourly value } \\ \text { hrc: } & \text { Recovered heat cooling } \\ \text { hrh: } & \text { Recovered heat heating } \\ m: & \text { Total consumption } \\ \text { orc: } & \text { Organic Rankine cycles } \\ \text { p: } & \text { Parasitic } \\ \text { pgu: } & \text { Power generation unit } \\ \text { pgum: } & \text { Capacity of PGU } \\ r: & \text { Recovered. }\end{array}$

Superscripts

SP: SP system.

\section{Data Availability}

All research data reported in this article are available. All of these data can be obtained free of charge. If you want to get these data, you can directly contact Yufang Chang; her email is changyf@hbut.edu.cn.

\section{Conflicts of Interest}

The authors declare that they have no conflicts of interest.

\section{Acknowledgments}

This work has been supported in part by the Green Industry Leading Program of Hubei University of Technology (CPYF2017003), the National Nature Science Fund of China (61601176) and the National Nature Science Fund of China (41601394).

\section{References}

[1] United State Environmental Protection Agency, Epa green building strategy, 2016, http://www.epa.gov/greenbuilding/ pubs/about.htm.

[2] Chinese Electricity Council, China Power Industry Annual Development Report 2011, China Market Press, Beijing, China, 2011.

[3] W. Jiang-Jiang, Z. Chun-Fa, and J. You-Yin, "Multi-criteria analysis of combined cooling, heating and power systems in different climate zones in China," Applied Energy, vol. 87, no. 4, pp. 1247-1259, 2010.

[4] Y. Shi, M. Liu, and F. Fang, Combined Cooling, Heating, and Power Systems: Modeling, Optimization, and Operation, John Wiley \& Sons, 2017.

[5] M. Liu, Y. Shi, and F. Fang, "Combined cooling, heating and power systems: a survey," Renewable \& Sustainable Energy Reviews, vol. 35, pp. 1-22, 2014.

[6] S. Murugan and B. Horák, "Tri and polygeneration systems-a review," Renewable \& Sustainable Energy Reviews, vol. 60, pp. 1032-1051, 2016.

[7] J.-J. Wang, Y.-Y. Jing, and C.-F. Zhang, "Optimization of capacity and operation for CCHP system by genetic algorithm," Applied Energy, vol. 87, no. 4, pp. 1325-1335, 2010.

[8] A. Mohamed, M. Hamdy, A. Hasan, and K. Sirén, “The performance of small scale multi-generation technologies in achieving cost-optimal and zero-energy office building solutions," Applied Energy, vol. 152, pp. 94-108, 2015.

[9] N. Fumo, P. J. Mago, and L. M. Chamra, "Analysis of cooling, heating, and power systems based on site energy consumption," Applied Energy, vol. 86, no. 6, pp. 928-932, 2009.

[10] F. Fang, Q. H. Wang, and Y. Shi, "A novel optimal operational strategy for the CCHP system based on two operating modes," IEEE Transactions on Power Systems, vol. 27, no. 2, pp. 1032-1041, 2012. 
[11] M. Liu, Y. Shi, and F. Fang, "A new operation strategy for CCHP systems with hybrid chillers," Applied Energy, vol. 95, pp. 164173, 2012.

[12] D. W. Wu and R. Z. Wang, "Combined cooling, heating and power: a review," Progress in Energy and Combustion Science, vol. 32, no. 5-6, pp. 459-495, 2006.

[13] E. A. Tora and M. M. El-Halwagi, "Integrated conceptual design of solar-assisted trigeneration systems," Computers \& Chemical Engineering, vol. 35, no. 9, pp. 1807-1814, 2011.

[14] X. Meng, F. Yang, Z. Bao, J. Deng, N. N. Serge, and Z. Zhang, "Theoretical study of a novel solar trigeneration system based on metal hydrides," Applied Energy, vol. 87, no. 6, pp. 2050-2061, 2010.

[15] F. Calise, M. Dentice d'Accadia, A. Palombo, and L. Vanoli, "Dynamic simulation of a novel high-temperature solar trigeneration system based on concentrating photovoltaic/thermal collectors," Energy, vol. 61, pp. 72-86, 2013.

[16] A. Nosrat and J. M. Pearce, "Dispatch strategy and model for hybrid photovoltaic and trigeneration power systems," Applied Energy, vol. 88, no. 9, pp. 3270-3276, 2011.

[17] J. Wang, Y. Dai, L. Gao, and S. Ma, "A new combined cooling, heating and power system driven by solar energy," Journal of Renewable Energy, vol. 34, no. 12, pp. 2780-2788, 2009.

[18] A. Baghernejad, M. Yaghoubi, and K. Jafarpur, "Exergoeconomic comparison of three novel trigeneration systems using SOFC, biomass and solar energies," Applied Thermal Engineering, vol. 104, pp. 534-555, 2016.

[19] K. F. Fong and C. K. Lee, "Investigation on zero grid-electricity design strategies of solid oxide fuel cell trigeneration system for high-rise building in hot and humid climate," Applied Energy, vol. 114, pp. 426-433, 2014.

[20] M. Puig-Arnavat, J. C. Bruno, and A. Coronas, "Modeling of trigeneration configurations based on biomass gasification and comparison of performance," Applied Energy, vol. 114, pp. 845856, 2014.

[21] P. J. Mago and L. M. Chamra, "Analysis and optimization of CCHP systems based on energy, economical, and environmental considerations," Energy and Buildings, vol. 41, no. 10, pp. 1099-1106, 2009.

[22] P. J. Mago, N. Fumo, and L. M. Chamra, "Performance analysis of CCHP and CHP systems operating following the thermal and electric load," International Journal of Energy Research, vol. 33, no. 9, pp. 852-864, 2009.

[23] S. Cao, A. Mohamed, A. Hasan, and K. Sirén, "Energy matching analysis of on-site micro-cogeneration for a single-family house with thermal and electrical tracking strategies," Energy and Buildings, vol. 68, pp. 351-363, 2014.

[24] J.-J. Wang, Y.-Y. Jing, C.-F. Zhang, and Z. J. Zhai, "Performance comparison of combined cooling heating and power system in different operation modes," Applied Energy, vol. 88, no. 12, pp. 4621-4631, 2011.

[25] N. Fumo and L. M. Chamra, "Analysis of combined cooling, heating, and power systems based on source primary energy consumption," Applied Energy, vol. 87, no. 6, pp. 2023-2030, 2010.

[26] P. J. Mago, L. M. Chamra, and J. Ramsay, "Micro-combined cooling, heating and power systems hybrid electric-thermal load following operation," Applied Thermal Engineering, vol. 30, no. 8-9, pp. 800-806, 2010.

[27] C. Z. Li, Y. M. Shi, and X. H. Huang, "Sensitivity analysis of energy demands on performance of CCHP system," Energy
Conversion and Management, vol. 49, no. 12, pp. 3491-3497, 2008.

[28] J. Wang, Z. J. Zhai, Y. Jing, and C. Zhang, "Particle swarm optimization for redundant building cooling heating and power system," Applied Energy, vol. 87, no. 12, pp. 3668-3679, 2010.

[29] Y.-Y. Jing, H. Bai, J.-J. Wang, and L. Liu, "Life cycle assessment of a solar combined cooling heating and power system in different operation strategies," Applied Energy, vol. 92, pp. 843-853, 2012.

[30] Y.-Y. Jing, H. Bai, and J.-J. Wang, "Multi-objective optimization design and operation strategy analysis of BCHP system based on life cycle assessment," Energy, vol. 37, no. 1, pp. 405-416, 2012.

[31] F. Fang, L. Wei, J. Liu, J. Zhang, and G. Hou, "Complementary configuration and operation of a CCHP-ORC system," Energy, vol. 46, no. 1, pp. 211-220, 2012.

[32] Z. Li, W. Li, and B. Xu, "Optimization of mixed working fluids for a novel trigeneration system based on organic Rankine cycle installed with heat pumps," Applied Thermal Engineering, vol. 94, pp. 754-762, 2016.

[33] Y. Huang, Y. D. Wang, S. Rezvani et al., "A techno-economic assessment of biomass fuelled trigeneration system integrated with organic rankine cycle," Applied Thermal Engineering, vol. 53, no. 2, pp. 325-331, 2013.

[34] F. A. Al-Sulaiman, I. Dincer, and F. Hamdullahpur, "Thermoeconomic optimization of three trigeneration systems using organic rankine cycles: part i - formulations," Energy Conversion and Management, vol. 69, pp. 199-208, 2013.

[35] H. Liu, T. Zhu, and T. Zhang, "Evaluation and analysis of CCHPORC system for different buildings in Shanghai," Zhongguo Dianji Gongcheng Xuebao/Proceedings of the Chinese Society of Electrical Engineering, vol. 36, no. 12, pp. 3198-3205, 2016.

[36] M. Geidl and G. Andersson, "Optimal power flow of multiple energy carriers," IEEE Transactions on Power Systems, vol. 22, no. 1, pp. 145-155, 2007.

[37] G. Chicco and P. Mancarella, "Matrix modelling of small-scale trigeneration systems and application to operational optimization," Energy, vol. 34, no. 3, pp. 261-273, 2009.

[38] US Department of Energy, "Energy plus," https://energyplus .net/.

[39] N. Fumo, P. Mago, and R. Luck, "Methodology to estimate building energy consumption using energyplus benchmark models," Energy and Buildings, vol. 42, no. 12, pp. 2331-2337, 2010.

[40] A. Antoniou and W.-S. Lu, Practical Optimization: Algorithms and Engineering Applications, Springer, New York, NY, USA, 2007. 


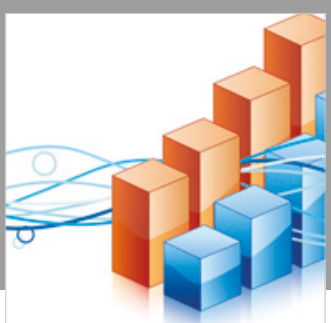

Advances in

Operations Research

\section{-n-m}
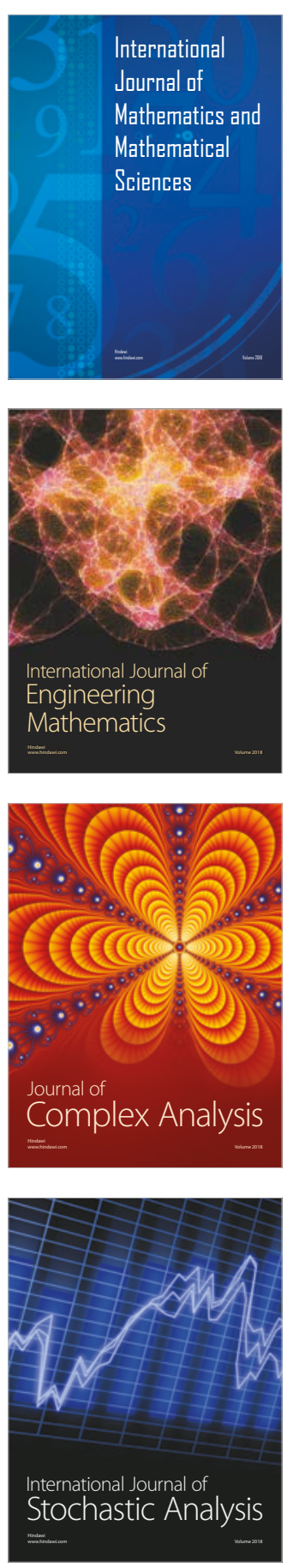
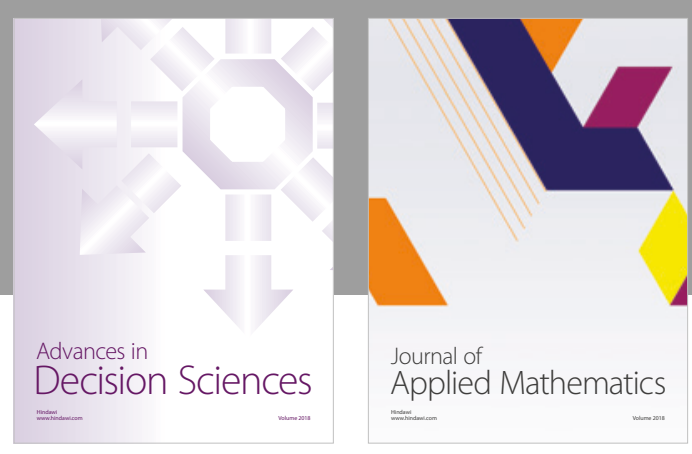

Journal of

Applied Mathematics
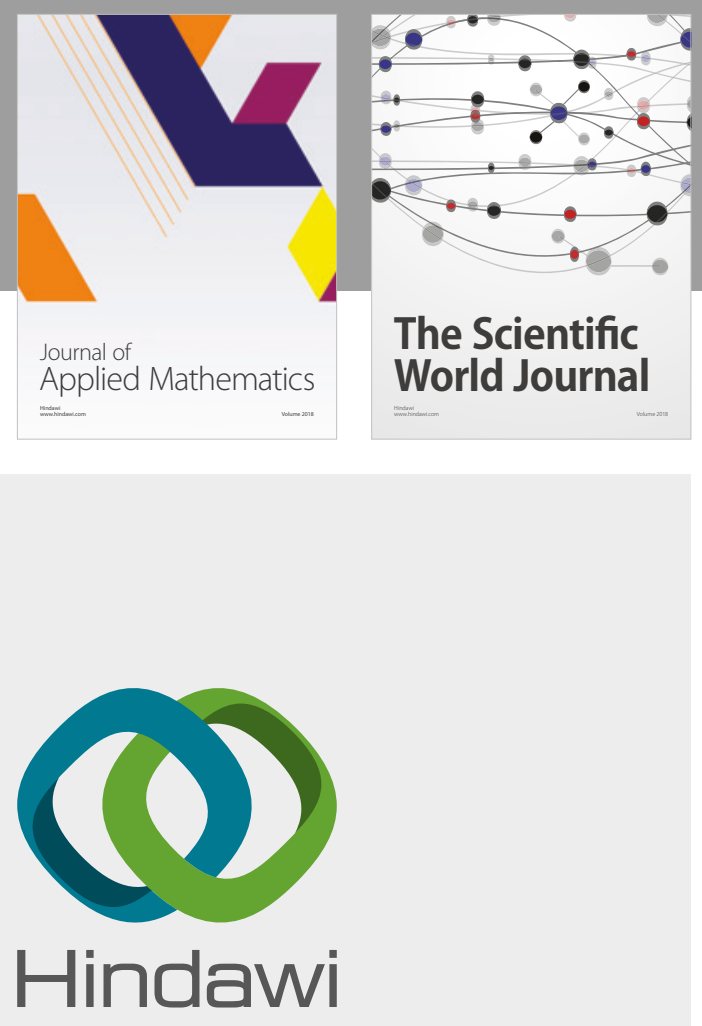

Submit your manuscripts at

www.hindawi.com

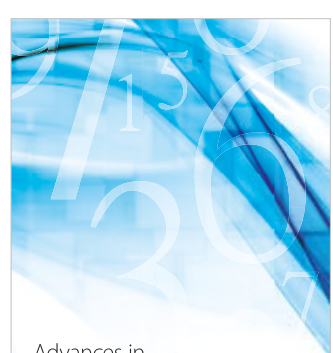

Advances in
Numerical Analysis
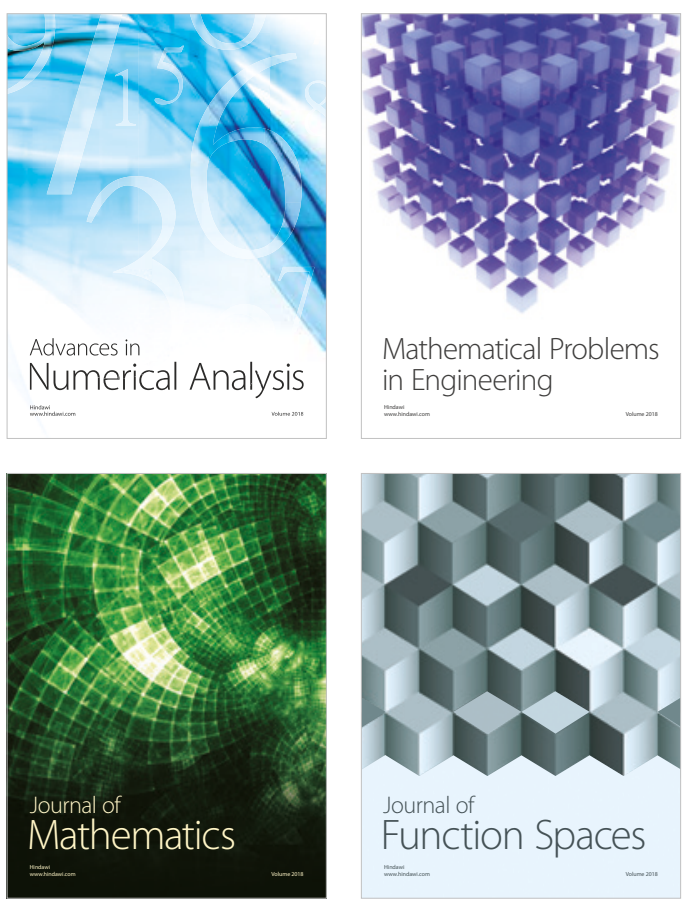

Mathematical Problems in Engineering

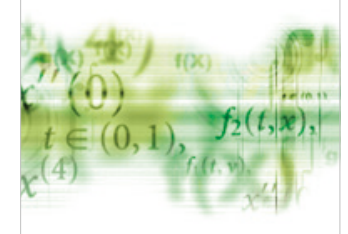

International Journal of

Differential Equations

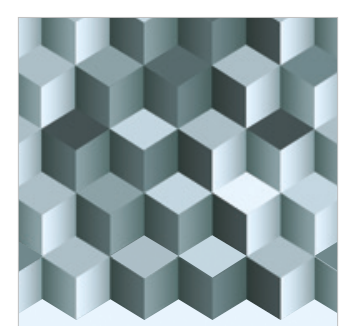

Journal of

Function Spaces
The Scientific

World Journal

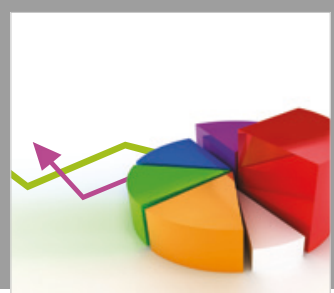

Journal of

Probability and Statistics
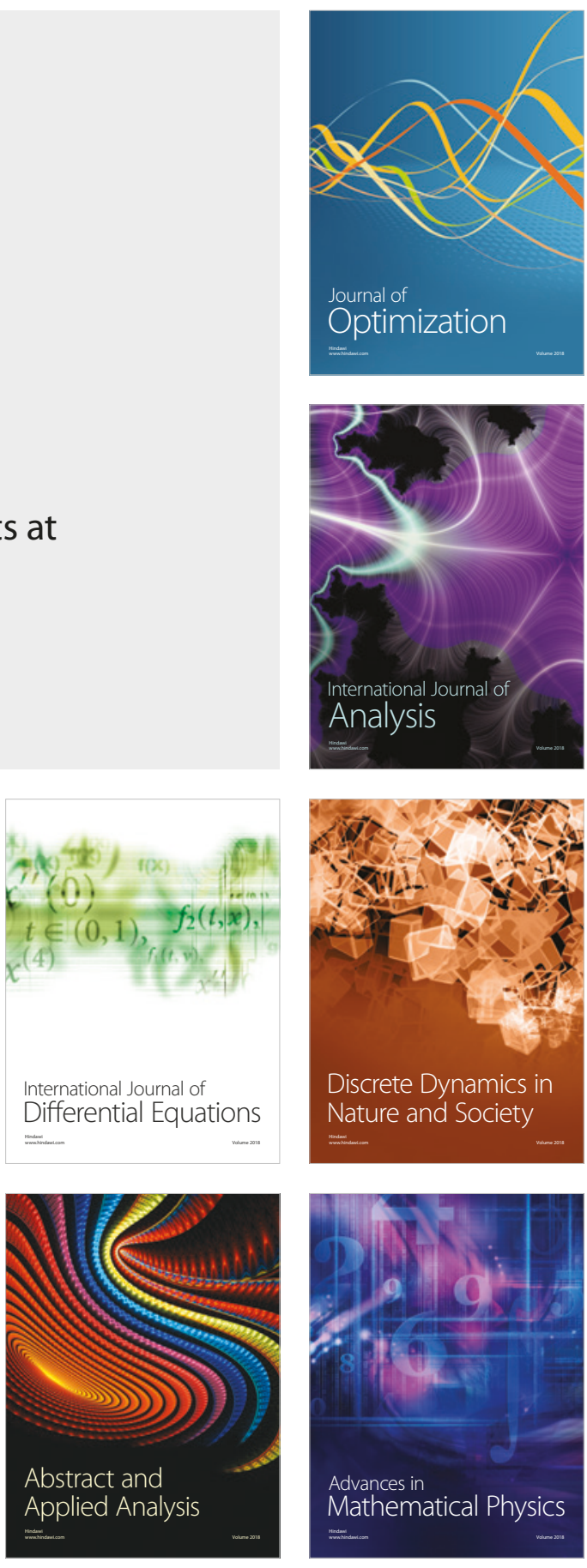